\title{
Partitioning of Localized and Diffuse Deformation in the Tibetan Plateau From Joint Inversions of Geologic and Geodetic Observations
}

John P. Loveless

Smith College, jloveles@smith.edu

Brendan J. Meade

Harvard University

Follow this and additional works at: https://scholarworks.smith.edu/geo_facpubs

Part of the Geology Commons

\section{Recommended Citation}

Loveless, John P. and Meade, Brendan J., "Partitioning of Localized and Diffuse Deformation in the Tibetan Plateau From Joint Inversions of Geologic and Geodetic Observations" (2011). Geosciences: Faculty Publications, Smith College, Northampton, MA. https://scholarworks.smith.edu/geo_facpubs/9 


\title{
Partitioning of localized and diffuse deformation in the Tibetan Plateau from joint inversions of geologic and geodetic observations
}

\author{
J. P. Loveless and B. J. Meade \\ Department of Earth and Planetary Sciences, Harvard University, 20 Oxford Street, \\ Cambridge, MA 02138 USA
}

\begin{abstract}
The spatial complexity of continental deformation in the greater Tibetan Plateau region can be defined as the extent to which relative motion of the Indian and Asian plates is partitioned between localized slip on major faults and distributed deformation processes. Potency rates provide a quantitative metric for determining the magnitudes of on-fault and diffuse crustal deformation, which are proportional to fault slip rates and strain rates within crustal micro-plates, respectively. We simultaneously estimate micro-plate rotation rates, interseismic elastic strain accumulation, fault slip rates on major structures, and strain rates within 24 tectonic micro-plates inferred from active fault maps in the greater Tibetan Plateau region using quasi-static block models constrained by interseismic surface velocities at 608 GPS sites and 9 Late Quaternary geologic fault slip rates. The joint geodetic-geologic inversion indicates that geologic slip rates are kinematically consistent with and result from differential micro-plate motions. Estimated left-lateral slip rates on the Altyn Tagh, west-central Kunlun, and Xianshuihe faults are relatively homogeneous along strike $(\sim 11.5,10.5$, and $12 \mathrm{~mm} / \mathrm{yr}$, respectively)
\end{abstract}


while segmentation of the eastern Kunlun fault by the intersecting Elashan and Riyueshan faults results in a decreased slip rate, consistent with geologic observations. The fraction, $\phi$, of total potency rate associated with intrablock strain, uncorrected for observational noise, ranges from 0.28 in the Himalayan Range block to 0.90 in the Aksai Chin block. Monte Carlo simulations are used to quantify the likelihood that internal deformation is statistically distinguishable from the uncertainties in geodetic velocities. These simulations show that internal block deformation is statistically significant only within the Himalayan Range Front (where internal deformation accounts for $\phi_{\mathrm{ID}}=0.10$ of block potency rate budget), west-central plateau $\left(\phi_{\mathrm{ID}}=0.73\right)$, Ganzi-Yushu/Xianshuihe (0.53), Burma (0.06), and Aksai Chin (0.64) blocks. In the other 19 tectonic micro-plates within the plateau region, estimated internal block potency is not currently distinguishable from the expected contribution of observational noise to residual velocities. Of the total potency budget within the Tibetan Plateau, $87 \%$ is taken up by slip on major faults, with the remaining $13 \%$ accommodated by internal processes at sub-block scale distinguishable from observational noise. The localization of the majority of plate boundary activity is also supported by the spatial distribution of modern and historical crustal earthquakes. Sixty-six percent of the total moment released by earthquakes in the CMT catalog and $89 \%$ of historical moment since 1900 has been released within $25 \mathrm{~km}$ of the major faults included in the block model, representing only $10 \%$ of the characteristic half-block length scale of $\sim 250 \mathrm{~km}$. The localization of deformation inferred from geologic, geodetic, and seismic observations suggests that forces applied to tectonic micro-plates drive fault system activity at the India-Asia collision 
zone over decadal to Quaternary time scales.

Keywords:

2

\section{Introduction}

Deformation at active continental plate boundaries has been approximated using the micro-plate and continuum end-member hypotheses. The former assumes that the majority of deformation is localized on an effectively countable number of major faults forming the boundaries of tectonic micro-plates (Avouac and Tapponnier, 1993; Shen et al., 2005; Meade, 2007; Thatcher, 2007), while the latter (Molnar, 1988; Flesch et al., 2001; England and Molnar, 2005) approximates the kinematics of continental deformation as diffusely distributed across active plate boundaries. The two concepts are linked by the idea that as more faults are introduced, individual microplate sizes decrease and, if fault slip rates become more homogeneous, the bulk behavior of a micro-plate system might approach the predictions of the continuum approximation (e.g., Thatcher, 2003, 2009). Debate about the adequacy of the two end-member approximations has been focused on the Tibetan Plateau (Molnar, 1988; Avouac and Tapponnier, 1993; Jade et al., 2004; Zhang et al., 2004; England and Molnar, 2005; Meade, 2007; Thatcher, 2007), which deforms to accommodate the relative motion between the Indian and Asian plates. Recent field-based investigations of slip rates on the Altyn Tagh fault have suggested upper crustal behavior that shows both strong localization on indentifiable faults and an unquantified amount of distributed deformation across wider shear zones (Cowgill et al., 2009). At a regional scale, wide aperture geodetic networks provide decadal surface velocity es- 
timates that can contribute to the determination of where on the spectrum between the two end-member deformation models present-day crustal activity lies. Global Positioning System (GPS) velocity fields in Tibet have been acquired through the interseismic phase of the earthquake cycle to avoid including the displacements from large earthquakes (Wang et al., 2001; Zhang et al., 2004; Gan et al., 2007). During the interseismic phase of the seismic cycle, elastic strain accumulation produces smoothly varying geodetic velocities near faults (e.g., Savage and Burford, 1973), which may extend as much as $500 \mathrm{~km}$ from active faults in Tibet (Bilham et al., 1997; Hilley et al., 2005; Feldl and Bilham, 2006). Because of the smooth velocity gradient across faults, as well as sparse geologic slip rate constraints on the most active faults in Tibet, GPS data have been interpreted either as reflecting diffuse deformation neglecting elastic strain accumulation (Jade et al., 2004; Zhang et al., 2004), or as consistent with block models that formally combine micro-plate rotations and earthquake cycle processes (Chen et al., 2004; Meade, 2007; Hilley et al., 2009).

Here we integrate the two end-member points of view, quantifying the spatial complexity of upper crustal deformation in Tibet using potency (geometric moment) rates to describe the partitioning of localized and diffuse processes. We simultaneously solve for micro-plate rotations, earthquake cycle effects, and internal block deformation with a quasi-static block model (Figure 1) constrained by both interseismic GPS velocities (Figure 2) and geologic fault slip rates (Table S1; Figure 3), allowing for analysis of recent deformation of the Tibetan Plateau region in a way that is consistent with decadal to Late Quaternary observations. Internal block strain rate estimates 
include a combination of unmodeled processes (e.g., other faults, folding) and observational noise. In order to isolate the proportion of the internal potency rate that is likely due to deformation, we estimate and remove the contribution to the residuals from observational noise using Monte Carlo simulations. Estimates of internal potency rates define quantitative bounds on the partitioning of continental deformation in the Tibetan Plateau region that are tested against earthquake spatial distribution and moment release estimates from historical and instrumental catalogs.

\section{Deformation partitioning analysis}

For a given fault system geometry and set of geodetic and geologic observations, the partitioning of localized and diffuse deformation can be determined from a comparison of potency rates, quantifying the magnitude of deformation associated with each process. The potency rate accommodated by on-fault processes, $P_{\mathrm{f}}$, is given by the product of fault area, $A$, and slip rate magnitude, $|\mathbf{s}|: P_{\mathrm{f}}=A|\mathbf{s}|$ (e.g., Aki and Richards, 1980). The potency rate associated with deformation processes occurring within crustal micro-plates, $P_{\mathrm{b}}$, can be derived from Kostrov's moment summation approach (Kostrov and Das, 1988) as twice the product of the internal block strain rate magnitude, $|\boldsymbol{\epsilon}|$, and the block volume, $V_{\mathrm{b}}: P_{\mathrm{b}}=2 V_{\mathrm{b}}|\boldsymbol{\epsilon}|$. Given $P_{\mathrm{f}}$ and $P_{\mathrm{b}}$ for each micro-plate, we calculate the potency rate partitioning value, $\phi$, as

$$
\phi=\frac{P_{\mathrm{b}}}{P_{\mathrm{f}}+P_{\mathrm{b}}} .
$$

68 In the limiting case where all deformation is localized as slip on faults included in a model, $P_{\mathrm{b}}=0$ and $\phi=0$. Conversely, if no deformation 
occurs on the included faults and internal micro-plate strain accounts for all potency, $P_{\mathrm{f}}=0$ and $\phi=1$. The quantity $\phi$ may be applied to any kinematic model of crustal motions to evaluate the partitioning of localized and diffuse deformation.

Both localized and diffuse potency rates can be determined from a joint block model analysis of geodetic and geologic data. Block models combine the assumption that fault slip rates result from differential micro-plate rotations with quasi-static earthquake cycle models to estimate fault slip rates and micro-plate rotation vectors using observations of interseismic deformation (e.g., Matsu'ura et al., 1986; Bennett et al., 1996; Prawirodirdjo et al., 1997; Souter, 1998; Murray and Segall, 2001; McCaffrey, 2002; Meade and Loveless, 2009). The linear forward problem can be written as $\mathbf{G m}=\mathbf{d}$, where $\mathbf{d}=\left[\mathbf{v ~ s}_{\mathrm{g}}\right]^{\top}$ is a vector comprising the nominally interseismic, geodetically observed surface velocity field, $\mathbf{v}$, and a set of geologically constrained fault slip rates, $\mathbf{s}_{\mathbf{g}} ; \mathbf{m}$ is a vector of Cartesian rotation vector components for all crustal micro-plates; and $\mathbf{G}$ is the Jacobian relating surface velocities and slip rate constraints to micro-plate rotation vectors and interseismic earthquake cycle deformation near locked (e.g., Savage and Burford, 1973), finite length (Okada, 1985), block-bounding faults (Matsu'ura et al., 1986). The estimated coupled micro-plate rotation vectors, $\hat{\mathbf{m}}$, are found using a weighted least-squares inversion, $\hat{\mathbf{m}}=\left(\mathbf{G}^{\top} \mathbf{W} \mathbf{G}\right)^{-1} \mathbf{G}^{\top} \mathbf{W} \mathbf{d}$, where $\mathbf{W}$ is a diagonal data weighting matrix with non-zero entries proportional to the inverse square of the reported geodetic velocity and geologic slip rate uncertainties. Kinematically consistent slip rate estimates, $\hat{\mathbf{s}}$, are determined by projecting the rotation vectors, $\hat{\mathbf{m}}$, describing relative micro-plate motions onto the 
three-dimensional fault system geometry.

Fault slip rates and geometry provide the information necessary to calculate the on-fault potency rate, $P_{\mathrm{f}}$, for each block,

$$
P_{\mathrm{f}}=\sum_{k=1}^{N_{\mathrm{f}}} \frac{\left|\mathbf{s}^{\{k\}}\right| L^{\{k\}} D^{\{k\}}}{2 \sin \delta^{\{k\}}},
$$

where $\left|\mathbf{s}^{\{k\}}\right|$ is the magnitude of the estimated slip rate for fault segment $k, L^{\{k\}}$ is the segment length, $D^{\{k\}}$ is the locking depth, $\sin \delta^{\{k\}}$ is the segment dip, and the summation is made over all $N_{\mathrm{f}}$ segments that bound the block. The division by 2 is required so that fault slip rates are not counted twice, corresponding to the two blocks that each fault segment bounds, when calculating potency rates.

Using the set of estimated micro-plate rotation vectors and the Jacobian, we calculate the predicted data vector, $\mathbf{G} \hat{\mathbf{m}}=\left[\begin{array}{l}\hat{\mathbf{v}} \\ \hat{\mathbf{s}}_{\mathrm{g}}\end{array}\right]^{\top}$, where $\hat{\mathbf{v}}$ is the predicted velocity field and $\hat{\mathbf{s}}_{\mathrm{g}}$ are the slip rate estimates on the geologically constrained segments. We carry out a Delaunay triangulation of GPS stations within each crustal block and, for each triangle, calculate the horizontal displacement rate gradient tensor, $\mathbf{D}$, of the residual velocity field, $\hat{\mathbf{r}}=\mathbf{v}-\hat{\mathbf{v}}$ (Figure 4a), with components $D_{i j}=\partial \hat{r}_{i} / \partial x_{j}$, where $\hat{r}_{i}$ is the residual velocity in the $i$ direction and $x_{i}$ is the station coordinate in the $j$ direction. We discard triangular elements whose edges intersect block boundaries, yielding a set of elements entirely internal to each block, and assume that $\mathbf{D}$ is constant throughout each triangle (Figure 4b). We decompose D into a symmetric strain rate tensor, $\boldsymbol{\epsilon}$, and antisymmetric rotation rate tensor, $\boldsymbol{\omega}$, and use the strain rate magnitude, $|\boldsymbol{\epsilon}|$, and volumes of the triangular prisms, $V_{\mathrm{t}}$ (triangles at the surface extruded to a depth equivalent to the estimated block-bounding 
fault locking depth), to calculate the potency rate, $P_{\mathrm{t}}=2 V_{\mathrm{t}}|\boldsymbol{\epsilon}|$. We calculate the total potency rate within each block, $P_{\mathrm{b}}$, by summing the $P_{\mathrm{t}}$ values for all $N_{\mathrm{t}}$ triangular prisms, scaling the contribution of each prism by its volume relative to the total volume of the tessellation prism, $V_{\mathrm{T}}$, and multiplying by the block volume, $V_{\mathrm{b}}$, given as the area inscribed by all block fault segments extruded to the fault locking depth depth and accounting for non-vertical fault dips,

$$
P_{\mathrm{b}}=V_{\mathrm{b}} \sum_{k=1}^{N_{\mathrm{t}}} \frac{P_{\mathrm{t}}^{\{k\}}}{V_{\mathrm{T}}} .
$$

As an alternative to the residual velocity field gradient calculation of internal potency rate, we estimate the best-fitting homogeneous spherical strain rate tensor, $\hat{\boldsymbol{\epsilon}}_{\mathrm{h}}$, for each micro-plate using an augmented Jacobian that explicitly includes a velocity field contribution from homogeneous strain (Savage et al., 2001; McCaffrey, 2005; Meade and Loveless, 2009) so that the intrablock potency rate, $P_{\mathrm{h}}$, is

$$
P_{\mathrm{h}}=2 V_{\mathrm{b}}\left|\hat{\boldsymbol{\epsilon}}_{\mathrm{h}}\right|
$$

The potency rate partitioning, $\phi$, for the homogeneous internal micro-plate strain rate case is calculated with Equation 1, replacing $P_{\mathrm{b}}$ with $P_{\mathrm{h}}$.

The residual velocity field, $\hat{\mathbf{r}}$, used to calculate the internal block potency rates, $P_{\mathrm{b}}$, includes contributions from unmodeled deformation processes and observational noise. To estimate the noise contribution to intrablock potency rates, we carry out Monte Carlo simulations using 1000 realizations of a synthetic observational noise velocity field. In each trial, a synthetic velocity field is realized as the sum of the velocity field predicted by the joint inversion 
reference model, $\hat{\mathbf{v}}$, and Gaussian noise, $\mathbf{n}, \hat{\mathbf{v}}^{\prime}=\hat{\mathbf{v}}+\mathbf{n}$. The predicted velocities $\hat{\mathbf{v}}$ are a function only of micro-plate rotations and earthquake cycle effects, with no contribution from observational noise (i.e., $P_{\mathrm{b}}=0$ ). For the north and east velocity components of each station, we generate noise with zero mean and standard deviation equal to the reported velocity component $1 \sigma(67 \%)$ uncertainties. We invert the noisy synthetic velocity field using the same block model and estimate the intrablock potency rate from the gradient of the resulting residual velocity field, $\hat{\mathbf{r}}^{\prime}$. In this case, the residual velocity field is due entirely to observational noise, with no contribution from intrablock deformation. For each block, we calculate the proportion of trial internal block potency rates from the noise perturbation analysis, $P_{\mathrm{b}}^{\mathbf{n}}$, that are less than the rate from the standard residual velocity field analysis (equation 3) or homogeneous strain rate tensor estimation (equation 4) and term this quantity the internal deformation likelihood (IDL):

$$
\mathrm{IDL}=\frac{N\left(P_{\mathrm{b}}^{\mathbf{n}}<P_{\mathrm{b}}\right)}{N_{\text {trials }}} .
$$

The IDL gives the likelihood that a fraction of $P_{\mathrm{b}}$ reflects deformation distinguishable from observational noise. We interpret blocks with high IDL as those that likely deform through physical mechanisms and processes not parametrized in the block model geometry. Conversely, the estimated internal potency rate of blocks with a zero (low) IDL can be explained exclusively (primarily) by the data noise contribution to the residual velocity field without unmodeled deformation sources.

The minimum magnitude of internal block deformation potency rate, $P_{\mathrm{ID}}=P_{\mathrm{b}}-\tilde{P}_{\mathrm{b}}^{\mathrm{n}}$, that is likely to be distinguishable from that associated 
with observational noise can be determined by subtracting the median value from all Monte Carlo trials, $\tilde{P}_{\mathrm{b}}^{\mathrm{n}}$, from the potency rate calculated from the joint inversion residual velocity field, $P_{\mathrm{b}}$. We use these noise-corrected internal potency rates to determine the partitioning ratios, $\phi_{\mathrm{ID}}$ (equation 1 , substituting $P_{\mathrm{ID}}$ for $P_{\mathrm{B}}$ ), that represent the amount of total deformation likely to be associated with intrablock deformation.

The joint geodetic-geologic inversion allows testing of basic block model assumptions. First, we evaluate whether or not sparse geologic slip rates on faults across the Tibetan Plateau can be predicted by a kinematically consistent block model with interconnected fault geometry. In general, each geologic slip rate estimate used to constrain the joint block model inversion is presented for an independent fault, without incorporating slip rates along-strike or on other structures. As possible explanations for the eastward decline in slip rate along the Kunlun fault, Kirby et al. (2007) suggested that slip may be transferred to adjacent structures and/or explained by differential rotation of crustal blocks north of the eastern Kunlun. The block model applies this concept to the entire plateau region, defining fault slip rates by projecting relative block rotations onto the three-dimensional fault system geometry. In a joint inversion, the rotations of adjacent blocks are coupled in two ways. Geologic observations define the slip rates on segments shared by two adjacent blocks, thereby constraining the relative rotational motion between them. Additionally, earthquake cycle effects across each fault segment contribute to GPS velocities at sites on the blocks sharing the boundary. The interseismic elastic deformation signal is a function of fault geometry and slip rate (e.g., Okada, 1985), and so velocities at GPS sites on adja- 
cent blocks spanning a boundary fault place constraints on the slip rate and hence the rotational motion of the blocks. As a second test of block model assumptions, we assess the kinematic compatibility between the sparse geologic data, which describe fault slip averaged over thousands of years, and spatially denser GPS observations measuring surface deformation on decadal time scales. The fit to each constraining data set depends on the weighting applied in the least squares inversion: lower weighting of the geologic slip rates results in improved fits to GPS at the expense of poorer fits to the slip rates. A model that achieves a good fit to both data sets simultaneously indicates both kinematic and temporal compatibility of geologic and geodetic observations.

\section{Kinematically consistent fault slip rates in the Tibetan Plateau}

A reference block model geometry (Figure 1) based on fault network connectivity suggested by the Taylor and Yin (2009) active fault map defines 29 micro-plates of which 24 comprise the greater Tibetan Plateau region. The plateau blocks range in size from $1.1 \times 10^{4} \mathrm{~km}^{2}$ to $3.4 \times 10^{6} \mathrm{~km}^{2}$, the smallest located between the Anninghe and Daliangshan segments of the XianshuiheXiaojiang (XS on Figure 1) fault system $\left(27-29^{\circ} \mathrm{N}\right)$ and the largest making up much of southeast China. (See description of block geometry in Appendix A.) All fault segments are assumed to dip vertically, except the Main Frontal Thrust (MFT) and Longmenshan fold-and-thrust belt (LM), which have dips of $7^{\circ} \mathrm{N}$ and $30^{\circ} \mathrm{W}$, respectively. Observations used to constrain the reference block model are nominally interseismic GPS velocities at 608 stations derived from three networks (Figure 2, Table S2; Vigny et al., 2003; 
Calais et al., 2006; Gan et al., 2007), combined by minimizing the residual velocities at collocated stations using a 6-parameter (rotation and translation) transformation, and 10 geologically constrained Late Quaternary slip rates. The slip rates used in this study include Late Quaternary rates with reported uncertainties on individual faults (Figure 3, Table S1; Allen et al., 1984; Lavé and Avouac, 2000; Brown et al., 2002; Van der Woerd et al., 2002; Wen et al., 2003; Haibing et al., 2005; Cowgill, 2007; Kirby et al., 2007; Li et al., 2009). We weight the geologic slip rate constraints 100 times more than the geodetic data, which results in approximately equal influence on the solution from the 9 geological data and the 1216 GPS observations (east and north velocity components at 608 stations, with uncertainties ranging from 0.1 to $4.8 \mathrm{~mm} / \mathrm{yr}$ ). Divergence-minimizing constraints are applied to all vertical faults within the plateau region to damp tensile motion; these constraints are weighted equally to the GPS data. We find an optimal uniform locking depth of $14 \mathrm{~km}$ for all faults, based on analysis of locking depth versus velocity residual statistics (Figure 5), which is broadly consistent with coseismic slip models for the 2001 Kokoxili (Kunlun) earthquake (Lasserre et al., 2005). The weighted least squares inversion yields a fit to the GPS data with a mean residual velocity magnitude of $2.50 \mathrm{~mm} / \mathrm{yr}$ and $\chi^{2}$ per degree-of-freedom of 2.35. These results indicate that geologic slip rates and their reported uncertainties, which range from $0.4-2 \mathrm{~mm} / \mathrm{yr}$ are kinematically consistent with micro-plate rotations and interseismic GPS velocities (see discussion; Figure 6).

Combining sparse geologic data with the denser GPS velocity fields, we estimate left-lateral slip of $9.1 \pm 0.7-9.5 \pm 0.6 \mathrm{~mm} / \mathrm{yr}$ on the multiple seg- 
ments representing the Karakax fault $(\mathrm{KX}), 10.8 \pm 0.2-11.3 \pm 0.2 \mathrm{~mm} / \mathrm{yr}$ on the central Altyn Tagh (AT) system, and $4.4 \pm 0.7 \mathrm{~mm} / \mathrm{yr}$ on the northeasternmost AT segment bounding the Qilian Shan block (G, Figure 3). The central AT is constrained by an $11.7 \pm 1.6 \mathrm{~mm} / \mathrm{yr}$ rate (Cowgill, 2007; Cowgill et al., 2009), which lies between the minimum and maximum latest Quaternary (ca. $6 \mathrm{ka}$ ) slip rate estimates of $9.4 \pm 0.9$ and $13.7 \pm 1.3 \mathrm{~mm} / \mathrm{yr}$ (Cowgill et al., 2009). Left-lateral slip rates are similarly constant along much of the Kunlun fault $(\mathrm{KN})$, ranging from $10.1 \pm 0.1$ to $11.3 \pm 0.6 \mathrm{~mm} / \mathrm{yr}$ between the junctions with the AT and Elashan faults $\left(\sim 100^{\circ} \mathrm{E}\right.$ longitude) as constrained by two geologic rates (Van der Woerd et al., 2002; Haibing et al., 2005). Segmentation of the eastern KN by the intersections with the Elashan and Riyueshan faults permits the slow slip constraints of Kirby et al. (2007) to be met $(5.0 \pm 0.4$ and $2.0 \pm 0.4 \mathrm{~mm} / \mathrm{yr})$ : estimated left-lateral slip rates on the easternmost $\mathrm{KN}$ are $1.7 \pm 0.1-5.7 \pm 0.1 \mathrm{~mm} / \mathrm{yr}$. In northeastern Tibet, we estimate $7.0 \pm 0.4-7.6 \pm 0.4 \mathrm{~mm} / \mathrm{yr}$ of left-lateral slip on the West Qinling fault, and on the Haiyuan fault (HY), we estimate left-lateral slip of $4.6 \pm 0.1-4.8 \pm 0.4 \mathrm{~mm} / \mathrm{yr}$, constrained by the average Quaternary rate of $4.5 \pm 1.1 \mathrm{~mm} / \mathrm{yr}$ estimated by Li et al. (2009). The faster estimated slip rates on the West Qinling and $\mathrm{HY}$ faults than on the eastern KN is consistent with the model of Duvall and Clark (2010) in which left-lateral slip is shifted north off of KN near its eastern extent. Our results suggest that the slip rate variations along strike KN can be explained by mechanical fault segmentation and differential micro-plate rotations, similar to the model proposed by Kirby et al. (2007). Along the Elashan fault, we estimate right-lateral slip of $0.8 \pm 0.9 \mathrm{~mm} / \mathrm{yr}$ (north) to $4.0 \pm 0.4 \mathrm{~mm} / \mathrm{yr}$ (south). On the subparallel 
Riyueshan fault, we estimate statistically insignificant left-lateral slip on the northern segment and $5.5 \pm 0.6 \mathrm{~mm} / \mathrm{yr}$ right-lateral slip on the segment south of the intersection with the West Qinling fault.

At the eastern margin of the Tibetan Plateau, the Xianshuihe-Xiaojiang fault system (XS) shows several branches and splays, including the Anninghe and Daliangshan segments, and Ganzi-Yushu fault (GY). Together, these faults accommodate a consistent rate of left-lateral slip from $23^{\circ}-35^{\circ} \mathrm{N}$. Slip on the segment south of the Anninghe-Daliangshan sliver is $11.3 \pm 0.3-$ $11.8 \pm 0.3 \mathrm{~mm} / \mathrm{yr}$, similar to the $13-15 \mathrm{~mm} / \mathrm{yr}$ rate across multiple branches of XS since the Late Pleistocene (Shen et al., 2003). To the north, slip is partitioned into $8.1 \pm 1.2-8.9 \pm 1.2 \mathrm{~mm} / \mathrm{yr}$ on the Anninghe segment and $4.2 \pm 1.3-4.4 \pm 1.3 \mathrm{~mm} / \mathrm{yr}$ on the Daliangshan segment. Northwest of these segments, XS slips at $10.7 \pm 0.6-12.3 \pm 0.3 \mathrm{~mm} / \mathrm{yr}$. Slip is again partitioned northwest of the intersection between XS and GY, with central GY slipping $10.2 \pm 0.2-13.3 \pm 0.4 \mathrm{~mm} / \mathrm{yr}$ as constrained by the $12.0 \pm$ $2.0 \mathrm{~mm} / \mathrm{yr}$ constraint of Wen et al. (2003), and XS slipping more slowly, ranging from $0.3 \pm 0.2 \mathrm{~mm} / \mathrm{yr}$ right-lateral to $0.8 \pm 0.3 \mathrm{~mm} / \mathrm{yr}$ left-lateral, with many segment slip rates smaller than their estimated uncertainties. Northwest of the intersection with the fault between JI and GY, GY slips left laterally at $0.9 \pm 0.5-1.5 \pm 0.6 \mathrm{~mm} / \mathrm{yr}$, slower than the $\sim 7 \mathrm{~mm} / \mathrm{yr}$ suggested by Wang et al. (2008), which we did not use as a constraint in the inversion owing to its lack of reported uncertainty. The along strike change in and partitioning of the XS/GY slip rate as a consequence of fault segmentation and branching is similar to the changes in slip rate on $\mathrm{KN}$ (Kirby et al., 2007) and the Big Bend region of the San Andreas fault in 
southern California (e.g., Meade and Hager, 2005). Slip rates on segments in this region provide a clear illustration of the kinematic consistency and path integral constraints inherent in block models. Consider the slip rates acting in a NW-SE direction, roughly parallel to GY and XS, between a point in the southeast corner of block $\mathrm{F}$ and a point in the east corner of block $\mathrm{D}$ following two different paths: one crossing northwestern GY, northwestern XS, and KN near the Van der Woerd et al. (2002) constraint, and the other crossing into block E, then the central GY, XS, and KN. The first path sums left-lateral slip of $\sim 1.5 \mathrm{~mm} / \mathrm{yr}$ on northwestern GY, $\sim 0 \mathrm{~mm} / \mathrm{yr}$ on $\mathrm{XS}$, and $\sim 11 \mathrm{~mm} / \mathrm{yr}$ on $\mathrm{KN}$ to give $\sim 12.5 \mathrm{~mm} / \mathrm{yr}$ total. The second path involves $\sim 8 \mathrm{~mm} / \mathrm{yr}$ of opening on the boundary between blocks $\mathrm{D}$ and $\mathrm{E}$, which is directed roughly perpendicular to the strike of GY, XS, and KN and acts in the opposite direction as left-lateral slip on those faults, $\sim 11 \mathrm{~mm} / \mathrm{yr}$ on central GY, $\sim 0 \mathrm{~mm} / \mathrm{yr}$ on XS, and $\sim 11 \mathrm{~mm} / \mathrm{yr}$ on $\mathrm{KN}$, summing to $\sim 14 \mathrm{~mm} / \mathrm{yr}$.

Along the southeast margin of the plateau, estimated right-lateral motion on the Red River fault (RR) is $5.4 \pm 0.4 \mathrm{~mm} / \mathrm{yr}$ northwest of the intersection with XS, at the upper range of the $2-5 \mathrm{~mm} / \mathrm{yr}$ Pliocene rate presented by Allen et al. (1984). Southeast of the XS intersection, RR slips right-laterally around $3 \mathrm{~mm} / \mathrm{yr}$. Estimated strike-slip on the Jiali fault (JI) is right-lateral, consistent with the sense of geologically recorded slip, but the estimated rates of $3.2 \pm 0.6-4.5 \pm 0.6 \mathrm{~mm} / \mathrm{yr}$ are considerably slower than the $10-100 \mathrm{kyr}$ 10-20 mm/yr right-lateral rates suggested by Armijo et al. (1989) across a suite of subparallel structures in this region on the basis of mapped offsets of inferred post-glacial landforms. However, we estimate faster right-lateral slip 
rates on a subparallel fault south of JI, roughly coincident with the Indus Yalu suture zone $(3.6 \pm 0.5-7.1 \pm 0.5 \mathrm{~mm} / \mathrm{yr})$, and on the continuation of JI around the eastern syntaxis $(17.1 \pm 0.4-18.7 \pm 0.5 \mathrm{~mm} / \mathrm{yr})$. Right-lateral slip rates on the Karakorum fault (KM) are $3.0 \pm 0.1-5.4 \pm 0.3 \mathrm{~mm} / \mathrm{yr}$, while the subparallel fault to its north slips right-laterally at $1.3 \pm 0.7-3.6 \pm 0.7 \mathrm{~mm} / \mathrm{yr}$. Taylor and Peltzer (2006) used satellite radar interferometry to estimate right-lateral slip of 2.1-4.1 mm/yr on the Lamu Co fault, located about $100 \mathrm{~km}$ southwest of the subparallel fault that we include in our model. On KM between the Longmu-Gozha (LG) and KX intersections, we estimate statistically negligible right-lateral slip, but to the northwest, between the KX and Tien Shan (TS) intersections, we estimate left-lateral slip of $3.7 \pm$ $0.5-6.9 \pm 0.5 \mathrm{~mm} / \mathrm{yr}$. This is inconsistent with the geologically recorded sense of slip but is mechanically consistent with the clockwise rotation of the Tarim Basin, which rotates about an Euler pole located in the Qilian Shan $\left(98.4^{\circ} \mathrm{E}, 37.9^{\circ} \mathrm{N}\right)$, predicting left-lateral slip on nearly all bounding faults. We estimate left-lateral slip of $13.2 \pm 1.0 \mathrm{~mm} / \mathrm{yr}$ on northeast LG (Gozha segment) and $2.3 \pm 0.9-2.8 \pm 0.9$ on southwest LG (Longmu segment). The Gozha segment rate is similar to the Quaternary rate of $8.3 \pm 2.7 \mathrm{~mm} / \mathrm{yr}$ estimated by Raterman et al. (2007) based on a kinematic analysis of slip rates on AT, KX, and KM. We estimate left-lateral slip on the fault between western JI and GY of $8.4 \pm 0.6-9.9 \pm 0.6 \mathrm{~mm} / \mathrm{yr}$.

Along the MFT, we estimate $6.6 \pm 0.6-22.4 \pm 0.3 \mathrm{~mm} / \mathrm{yr}$ of reverse motion, from west to east, constrained by the $21.0 \pm 1.5 \mathrm{~mm} / \mathrm{yr}$ rate of Lavé and Avouac (2000) around $85^{\circ} \mathrm{E}$ longitude (Figure $3 \mathrm{~b}$ ). The gradient in slip rates results from a local Euler pole of the Indo-Australian plate $\left(62.57 \pm 0.79^{\circ} \mathrm{E}\right.$, 
$35.17 \pm 1.05^{\circ} \mathrm{N}, 0.53 \pm 0.01^{\circ} / \mathrm{Myr}$ relative to the Himalayan Range Front block, and $31.84 \pm 1.44^{\circ} \mathrm{E}, 31.73 \pm 0.37^{\circ} \mathrm{N}, 0.47 \pm 0.01^{\circ} / \mathrm{Myr}$ relative to the stable Eurasian GPS reference frame). The India-Eurasia pole is located closer to the Himalaya than the also disparate previous geodetic estimates of $11.62^{\circ} \mathrm{E}, 28.56^{\circ} \mathrm{N}, 0.36^{\circ} / \mathrm{Myr}$ (Sella et al., 2002) and $17.65^{\circ} \mathrm{W}, 24.22^{\circ} \mathrm{N}$, $0.32 \pm 0.02^{\circ} / \mathrm{Myr}$ (Prawirodirdjo and Bock, 2004). Across the Longmenshan fold-and-thrust belt, where there are no known geologic slip rate constraints, we estimate $3.0 \pm 0.6-3.9 \pm 0.5 \mathrm{~mm} / \mathrm{yr}$ of reverse motion, along with $2.1 \pm 0.4-$ $2.8 \pm 0.4 \mathrm{~mm} / \mathrm{yr}$ of right-lateral slip, consistent with the oblique coseismic slip that characterized the 2007 Wenchuan earthquake both at depth (e.g., Feng et al., 2010) and at the surface (e.g., Xu et al., 2009).

\section{Deformation partitioning in the Tibetan Plateau}

The kinematically consistent slip rates presented above reflect recent deformation of the Tibetan Plateau region occurring on the major structures included in the model under the assumption that decadal and Quaternary rates are consistent through time. The block model formulation is predicated on the idea that interseismic deformation as recorded by the constraining GPS data is the result of micro-plate rotations and earthquake cycle processes along major faults. Residual GPS velocities, therefore, reflect deformation associated with unparametrized processes. By comparing the potency rates on major faults (Equation 2) to those calculated using the residual velocity field within each block (Equation 3) through calculation of the potency rate partitioning value, $\phi$ (Equation 1), the magnitude of deformation sources not associated with the block model geometry can be determined. 
Potency rate partitioning values for the joint geodetic-geologic inversion, assuming no observational noise, range from $\phi=0.28$ in the Himalayan Range block (labeled A in Figure 1), where the fault area of the shallowly dipping MFT results in a large on-fault potency rate, to 0.90 in the Aksai Chin block (W; Figure 7a). Aside from these blocks, the west-central plateau block (D, $\phi=0.86)$, and peripheral South China block $(\mathrm{S}, \phi=0.25)$, $\phi$ is in the range of $\sim 0.50-0.75$ for all other tectonic micro-plates. Potency magnitude and partitioning values from an inversion of geodetic data alone are similar to those from the joint geologic-geodetic inversion (Table 1; Figure S1a), with a mean magnitude of change in partitioning ratio of $4.5 \%$ relative to the joint inversion values. Potency rate partitioning values calculated using the best-fitting homogeneous strain rate tensor estimate (e.g., McCaffrey, 2005) are an average of $44.0 \%$ lower than the values from the full residual velocity field gradient, averaging $\phi=0.36$, and are lower in all blocks except the Laos block (Table 1; Figure S2a).

The IDL (equation 5) can be interpreted as the likelihood that the internal block potency rate estimate reflects deformation distinguishable from the null hypothesis that residual velocities reflect only observational noise (Table 1; Figure $7 \mathrm{~b}$ ). The frequency distributions of simulated noise potency rates from the Monte Carlo simulations are shown for select blocks in Figure $7 \mathrm{~d}-$ i. We estimate high IDL $(\sim 0.5$ or greater $)$ in the Himalayan Range $(\mathrm{A})$, Jiali (C), west-central plateau (D), Ganzi-Xianshuihe sliver (N), Burma (U), and Aksai Chin (W) blocks and IDL $\leq 0.05$ in the Karakorum (B), Qaidam Basin (F), most of the northeastern blocks (H, K, L, and M), the Lugu Lake (O), Eastern Kunlun (P), south China (S), Yunnan (T), and Tarim 
Basin $(\mathrm{X})$ blocks. Intermediate values of IDL between $\sim 0.1-0.4$ characterize the east-central plateau (E), Qilian Shan (G), Gonghe Nan Shan (I), West Qinling (J), Longmenshan (Q), Anninghe-Daliangshan (R), and Laos (V) blocks. The estimated IDL from the geodetic-only inversion differs from that of the joint inversion by $<0.05$ in general (Table 1). For the homogeneous estimated strain rate tensor calculation, we compare $P_{\mathrm{h}}$ with the $P_{\mathrm{b}}^{\mathrm{n}}$ values from the Monte Carlo simulation of data noise without estimating $\hat{\boldsymbol{\epsilon}}_{\mathrm{h}}$; IDL values are $<0.1$ for all blocks except the Jiali $(\mathrm{C} ; 0.16)$ and Aksai Chin (W; 0.62) (Figure S2b).

Zero to low IDL $(<0.1)$ characterizes the Tarim Basin (block X), Qaidam Basin (block F), Ordos Plateau (block L), and south China (block S), including the Sichuan Basin. Internal potency rates in these and the other low IDL blocks cannot currently be distinguished from observational noise in the GPS data, without intrablock deformation. The lack of internal deformation may be consistent with gravity-based studies suggesting greater elastic thickness beneath the Tarim and Qaidam Basins (Braitenberg et al., 2003) and regional tomographic studies indicating high seismic velocity roots beneath the Ordos Plateau and Sichuan Basin of the south China block (Yangtze Craton) (Lebedev and Nolet, 2003; Li et al., 2008).

High (greater than $\sim 0.5$ ) IDL blocks are likely to be accommodating deformation internally. The Himalayan Range Front block may not act as a contiguous unit between the western to eastern syntaxes but may be segmented by normal faults striking roughly orthogonal to the HRF (e.g., Langin et al., 2003). The same is true for the Jiali block (C): residual velocity vectors suggest that a north striking fault around the longitude of Lhasa $\left(90^{\circ} \mathrm{E}\right)$ 
may divide the block. Including such a structure reduces the magnitude and systematic orientation of residual velocities but predicts left-lateral slip on the Jiali fault, opposite the sense inferred from geologic observations (e.g., Armijo et al., 1989). Including the Riyueshan fault between the Gonghe Nan Shan and West Qinling blocks (I and J) reduces the magnitude of residual velocities relative to a test model in which the fault is absent while improving the agreement between estimated slip rates and geologic constraints (Kirby et al., 2007) on segments of the eastern KN. Deformation within these modeled micro-plates may alternatively be accommodated on multiple discrete structures, such as the thrust faults near $103^{\circ} \mathrm{E}, 35^{\circ} \mathrm{N}$ (Qinghai Bureau of Geology and Mineral Resources of Qinghai Province, 1991). The west-central plateau block (D) also shows large magnitude, systematically east trending residual velocities (Figure 4a), which may suggest that additional structures divide the block into smaller parts that rotate independently. While there are several candidate structures for doing so (Figure 1), GPS data in this region are sparsely distributed and so slip rates on such structures would be poorly resolved. In the Ganzi-Xianshuihe sliver block (N), large residual velocities (mean magnitude of $5.2 \mathrm{~mm} / \mathrm{yr}$ ) and IDL $\geq 0.89$ are found in both the joint geologic-geodetic and geodetic-only inversions, suggesting that some internal deformation takes place within this block and/or the reference block geometry is locally incorrect.

The internal deformation potency rate distinguishable from observational noise, $P_{\mathrm{ID}}$, is positive for only the Himalayan Range, west-central plateau, Ganzi-Xianshuihe, Burma, and Aksai Chin blocks (1; Figure 7c). Only these blocks contribute to the diffuse deformation budget of the Tibetan Plateau. 
The total internal deformation potency rate partitioning ratio throughout the entire plateau region, $\phi_{\text {plateau }}$, given as

$$
\phi_{\text {plateau }}=\frac{\sum P_{\mathrm{ID}},}{\sum P_{\mathrm{ID}}+\sum P_{\mathrm{F}}},
$$

where $P_{\mathrm{ID}}$ is set to zero in those blocks with IDL $\leq 0.5$ and the sums are taken over all plateau blocks, is 0.13 , meaning that as much as $87 \%$ of observed deformation can be described by processes occurring on the major faults included in the block model when observational noise is formally considered.

Estimates of intrablock and on-fault potency rates are a function of the realized fault system geometry. In the reference block model geometry, we included select structures whose continuity is currently unclear in order to reduce the systematic orientation and large magnitude of some clusters of residual velocity vectors. Excluding certain structures reduces the overall quality of fit to the GPS data, which in general yields larger $P_{\mathrm{b}}, \phi$, IDL, and $\phi_{\mathrm{ID}}$. Removing the structure connecting JI and GY and that connecting JI and LG results in a central Tibet block $\sim 10^{6} \mathrm{~km}^{2}$ in area. A test joint inversion using this fault system geometry estimates slip rates similar to the reference model, but with a faster western $\mathrm{KN}(\sim 14 \mathrm{~mm} / \mathrm{yr}$ left-lateral), faster KM (up to $7 \mathrm{~mm} / \mathrm{yr}$ right-lateral), slower JI ( 1 mm/yr right-lateral), and LG and northwestern GY that are consistent in slip rate along strike ( $\sim 12 \mathrm{~mm} / \mathrm{yr}$ and $\sim 5 \mathrm{~mm} / \mathrm{yr}$ left-lateral, respectively). The test model gives $\phi=0.71$ for the central block, equal to the volume-weighted average of the partitioning values in the three corresponding blocks of the reference geometry. The IDL of the combined central plateau block is 0.69 , suggesting the additional active structures included in the reference model. IDL in the Karakorum (B) and east-central plateau (E) blocks of the reference model 
is notably lower ( 0.05 and 0.07 , respectively) than that in the west-central plateau block (D, 0.98), which suggests that further subdivision of the westcentral plateau block may be possible with the advent of sufficient geodetic and/or geologic data. The comparison between the degraded and reference models serves as an example of how the potency rate partitioning analysis can guide the identification of active fault system structures.

Despite moderate to high IDL in the Anninghe-Daliangshan sliver (0.12), Aksai Chin block (0.68), and Ganzi-Xianshuihe sliver (0.95), internal potency rates may not represent internal deformation and may instead be an artifact of the strain calculation: at most three Delaunay strain rate triangles can be constructed from the GPS stations that lie within these blocks. The standard deviations of the Monte Carlo simulated potency rates in these blocks are the greatest of all blocks, exceeding $40 \%$ of the mean trial potency rate, $\bar{P}_{\mathrm{b}}^{\mathrm{n}}$ (as compared to a mean of $18.5 \%$ for all other blocks and $22.0 \%$ for all blocks). Trial intrablock potency rate variance decreases with the number of stations in the blocks (Figure S3a) and in general decreases with increasing proportion of block volume represented by Delaunay triangles (Figure S3b).

\section{Potency rates and earthquake moment release}

As an independent indicator of the partitioning between localized and diffuse deformation, we examine the spatial distribution of earthquakes in the Global CMT catalog since 1976 and a 20th century historical catalog (Holt et al., 1995), calculating the distance between each event and the closest block boundary (Figure 8). In the CMT catalog, 476 earthquakes with depth $\leq 33 \mathrm{~km}$ and $\mathrm{M}_{\mathrm{W}} \geq 5.0$ have occurred within the plateau blocks, 
half of which were within $50 \mathrm{~km}$ of a modeled boundary (Figure 9a). Sixtysix percent of the cumulative moment release since 1976 has occurred in events within $25 \mathrm{~km}$ of a block boundary, and 96\% within $100 \mathrm{~km}$ (Figure $9 \mathrm{~b})$. Thirty-six major $\left(\mathrm{M}_{\mathrm{W}} \geq 6.4\right)$ historical earthquakes have occurred since 1900 (Holt et al., 1995) in the plateau blocks, 25 of which were within $50 \mathrm{~km}$ of the nearest block boundary (Figure 9c). Assuming that the two $\mathrm{M}_{\mathrm{W}}=8.3$ Himalayan Range Front events of 1905 and 1934, and the 1950 $\mathrm{M}_{\mathrm{W}}=8.5$ Medog earthquake took place on the MFT (e.g., Bilham et al., 2001), which dips beneath the events' epicenters (i.e., segment-earthquake distance of zero), $89 \%$ of the cumulative historic moment release was released within $25 \mathrm{~km}$ of faults in the reference block model (Figure 9d). We define a mean block length scale as half the square root of the mean block area, reflecting the average distance from a block center to its boundaries. This measure is $253 \mathrm{~km}$ (red vertical line in Figure 9), 10 times larger than the $25 \mathrm{~km}$ within which $86 \%$ of combined historical and modern moment has been released.

We suggest that earthquakes located within $\sim 25 \mathrm{~km}$ of a block boundary can be considered to have occurred on a modeled fault segment, given errors in earthquake location and the approximations we make in generating the block geometry from the discontinuous active fault map. Earthquake locations deduced from satellite interferometry suggest that, in remote locations, uncertainties in CMT locations may be as much as $\sim 40-50 \mathrm{~km}$ (Lohman and Simons, 2005; Pritchard et al., 2006). That $66 \%$ of all modern and $89 \%$ of historical moment release occurred within this $25 \mathrm{~km}$ range (Figure 9) indicates that the block boundaries chosen for our reference model represent the 
most important structures in the Tibetan Plateau region in terms of seismic moment release. This proximity of seismic moment release to major faults in Tibet, independent of geodetic data and the mechanical assumptions of the block model, gives an additional metric of the importance of major faults in accommodating active deformation. The moment released more than $25 \mathrm{~km}$ from block model boundaries can be interpreted as intrablock deformation occurring on faults below the resolution of the model and could be used to guide changes to the model geometry, particularly in places where active fault maps based on field geology may be incomplete.

\section{Discussion}

We have shown that both Holocene-Quaternary geologic slip rates and decadal interseismic GPS velocities are consistent with a model of Tibet composed of rotating tectonic micro-plates. Estimation of fault slip rates and internal block strain rates provides a means for quantitatively determining the potency rates associated with localized and diffuse crustal deformation processes. Given current geodetic coverage and sparse geologic slip rate estimates, internal deformation is statistically distinguishable from observational noise only within the Himalayan Range, west-central plateau, Ganzi-Xianshuihe sliver, Burma, and Aksai Chin blocks. Our results suggest that fault slip on the boundaries of 24 micro-plates, interseismic elastic strain accumulation, and consideration of observational noise can describe $87 \%$ of surface motion of the greater Tibetan Plateau region as recorded in existing GPS data. Similarly $>86 \%$ of seismic moment release in the combined modern and historical earthquake catalog has occurred within $25 \mathrm{~km}$ of block 
model boundaries, offering additional evidence that major faults accommodate the majority of active deformation in Tibet. How the accommodation of active continental deformation is distributed has substantial implications for the evolution of plate boundary zones. If deformation is accommodated primarily by slip localized on major active faults, as is implied by the potency rate partitioning results, and continental tectonics in general are controlled by the strength of the crust (e.g., Jackson, 2002), then understanding the interactions among major structures is key to understanding the evolution of plate boundaries. Block models provide an interpretation of recent plate boundary activity, but the fault system geometry may not be sustainable over long periods of time (Cowgill et al., 2009; Taylor and Yin, 2009): some faults may become inactive, shifting activity onto adjacent structures, and fault intersections change as the micro-plates they bound undergo finite rotations. Here we have made the assumption that time variation in fault slip rates, from decadal to Quaternary scales, is negligible. The fact that both decadal geodetic velocities sampled only over a fraction of an individual earthquake cycle and Holocene-Quaternary fault slip rates integrated over multiple earthquake cycles can be simultaneously satisfied using a microplate rotation model suggests that this assumption cannot be falsified at the scale of this study. While time variable fault activity has been documented in western North America (Friedrich et al., 2003; Dolan et al., 2007), geologic evidence for such behavior in Tibet (along the Karakorum fault) is equivocal due to conflicting slip rate estimates over similar time periods (Brown et al., 2002; Chevalier et al., 2005).

While we have shown that the geologic, geodetic, and seismic observa- 
tions of the upper crustal activity in Tibet can be simultaneously explained by models combining the rotations of tectonic micro-plates and earthquake cycle processes, the forces that drive these motions are currently less clear. The force balance on tectonic plates has been debated for over four decades (Solomon and Sleep, 1974; Forsyth and Uyeda, 1975; Conrad and LithgowBertelloni, 2002; Bird et al., 2008) and the same concepts can be applied to smaller continental micro-plates (Fay and Humphreys, 2005; Copley et al., 2010). A simple analytic theory describing the torque balance on an isolated ellipsoidal micro-plate rotating atop a viscous substrate about a vertical axis located at the micro-plate centroid suggests that the ratio of basal to edge torques, $\theta \sim h_{\mathrm{uc}} \tau / l \epsilon \eta$, decreases linearly with decreasing micro-plate length scale (Lamb, 1994), where $l$ is the characteristic block length scale, $\epsilon$ is the strain rate in the viscous substrate, $\eta$ is the viscosity of the viscous substrate, $h_{\mathrm{uc}}$ is the thickness of the upper crust (micro-plate), and $\tau$ is the average shear stress acting on the sides of the block. Our kinematic models based on the Taylor and Yin (2009) fault map constrain $l$ to be $\sim 250 \mathrm{~km}$. Estimates of lower crustal viscosity in Tibet are highly variable, with estimates from topographically constrained lower crustal flow models ranging from $1 \times 10^{21} \mathrm{~Pa}$-s at the northern plateau margin to $1 \times 10^{17} \mathrm{~Pa}$-s at the southeastern margin (Clark and Royden, 2000). Assuming simple Couette flow for the lower crust, strain rates are given by the differential velocity, $\Delta v$, across the lower crust of $\sim 20 \mathrm{~mm} / \mathrm{yr}$ (i.e., the half of the India-Asia convergence rate not consumed at the Himalayan Range front) divided by its thickness, $h_{\mathrm{lc}}=10-30 \mathrm{~km}$ (Royden et al., 1997). Estimates of the depth extent of coseismic slip distributions, and interseismic locking depth estimates 
presented here suggest that the thickness of the seismogenic upper crust is $h_{\mathrm{uc}} \approx 10-20 \mathrm{~km}$. The shear stress acting on faults is the coefficient of friction multiplied by the effective normal stress, $\tau=\mu \sigma_{\text {eff }}$, where $\mu$ ranges from 0.01 to 0.1 (Suppe, 2007). The effect of pore fluid pressure may reduce the normal stress due to lithostatic loading, reducing to $\sigma_{\mathrm{eff}}=\rho(1-\lambda) g h_{\mathrm{uc}}$, where $\rho=2750 \mathrm{~kg} / \mathrm{m}^{3}$ is upper crustal density, $\lambda$ is the ratio of fluid to lithostatic pressure $(\lambda=0.36$ for hydrostatic fluid pressures, assuming zero porosity), and $g$ is gravity. Combining these parameter estimates gives a broad range for the ratio of edge/basal torques, $\theta \sim h_{\mathrm{uc}}^{2} h_{\mathrm{lc}} \mu \rho(1-\lambda) g / l \eta \Delta v$, suggesting that edge forces and basal tractions are equally likely to be the dominant driver of recent deformation within the Tibetan Plateau. A refined estimate of the upper crustal torque balance is possible adopting parameters necessary to initiate and sustain channel flow (Beaumont et al., 2001). In this case, $h_{\mathrm{uc}}=25 \mathrm{~km}, h_{\mathrm{lc}}=25 \mathrm{~km}$, and $\eta=1 \times 10^{19}$ Pa-s, giving a much narrower range of $\theta \sim 1-10$, suggesting that for tectonic micro-plates of the scale used in our model (or smaller) edge forces are likely to be comparable in size to basal tractions. The relative importance of edge forces increases with decreasing lower crustal viscosity and smaller micro-plate sizes in this simple model where micro-plates rotate about a vertical axis at their centroids. The combination of localized deformation and a relatively weak lower crust suggests that to understand the evolution of the surface of the Tibetan Plateau will require a new class of dynamic models that explicitly include interacting tectonic micro-plate systems and coupling between the upper and lower crust. 


\section{References}

Aki, K., Richards, P. G., 1980. Quantitative Seismology: Theory and Methods. Vol. 1. W. H. Freeman, San Francisco.

Allen, C. R., Gillespie, A. R., Yuan, H., Sieh, K. E., Buchun, Z., Chengnan, Z., 1984. Red River and associated faults, Yunnan Province, China: Quaternary geology, slip rates, and seismic hazard. Geological Society of America Bulletin 95 (6), 686-700.

Armijo, R., Tapponnier, P., Tonglin, H., 1989. Late Cenozoic right-lateral strike-slip faulting in southern Tibet. Journal of Geophysical Research 94 (B3), 2787-2838.

Avouac, J. P., Tapponnier, P., 1993. Kinematic Model of Active Deformation in Central-Asia. Geophysical Research Letters 20 (10), 895-898.

Beaumont, C., Jamieson, R. A., Nguyen, M. H., Lee, B., 2001. Himalayan tectonics explained by extrusion of a low-viscosity crustal channel coupled to focused surface denudation. Nature 414 (6865), 738-742.

Bennett, R. A., Rodi, W., Reilinger, R. E., 1996. Global positioning system constraints on fault slip rates in southern California and northern Baja, Mexico. Journal of Geophysical Research 101 (B10), 21943-21960.

Bilham, R., Gaur, V. K., Molnar, P., 2001. Himalayan Seismic Hazard. Science 293 (5534), 1442-1444.

Bilham, R., Larson, K., Freymueller, J., Jouanne, F., LeFort, P., Leturmy, P., Mugnier, J. L., Gamond, J. F., Glot, J. P., Martinod, J., Chaudury, 
N. L., Chitrakar, G. R., Gautam, U. P., Koirala, B. P., Pandey, M. R., Ranabhat, R., Sapkota, S. N., Shrestha, P. L., Thakuri, M. C., Timilsina, U. R., Tiwari, D. R., Vidal, G., Vigny, C., Galy, A., deVoogd, B., 1997. GPS measurements of present-day convergence across the Nepal Himalaya. Nature 386 (6620), 61-64.

Bird, P., Liu, Z., Rucker, W. K., 2008. Stresses that drive the plates from below: Definitions, computational path, model optimization, and error analysis. Journal of Geophysical Research 113 (B11).

Braitenberg, C., Wang, Y., Fang, J., Hsu, H., 2003. Spatial variations of flexure parameters over the Tibet-Quinghai plateau. Earth and Planetary Science Letters 205 (3-4), $211-224$.

Brown, E. T., Bendick, R., Bourles, D. L., Gaur, V., Molnar, P., Raisbeck, G. M., Yiou, F., 2002. Slip rates of the Karakorum fault, Ladakh, India, determined using cosmic ray exposure dating of debris flows and moraines. Journal of Geophysical Research 107 (B9).

Calais, E., Dong, L., Wang, M., Shen, Z., Vergnolle, M., 2006. Continental deformation in Asia from a combined GPS solution. Geophysical Research Letters 33.

Chen, Q. Z., Freymueller, J. T., Wang, Q., Yang, Z. Q., Xu, C. J., Liu, J. N., 2004. A deforming block model for the present-day tectonics of Tibet. Journal of Geophysical Research 109 (B1).

Chevalier, M. L., Ryerson, F. J., Tapponnier, P., Finkel, R. C., Van der Woerd, J., Li, H. B., Liu, Q., 2005. Slip-rate measurements on the Karakorum 
Fault may imply secular variations in fault motion. Science 307 (5708), 411-414.

Clark, M. K., Royden, L. H., 2000. Topographic ooze: Building the eastern margin of Tibet by lower crustal flow. Geology 28 (8), 703-706.

Conrad, C. P., Lithgow-Bertelloni, C., 2002. How mantle slabs drive plate tectonics. Science 298, 207-209.

Copley, A., Avouac, J.-P., Royer, J.-Y., 2010. India-Asia collision and the Cenozoic slowdown of the Indian plate: Implications for the forces driving plate motions. Journal of Geophysical Research 115.

Cowgill, E., 2007. Impact of riser reconstructions on estimation of secular variation in rates of strike-slip faulting: Revisiting the Cherchen River site along the Altyn Tagh Fault, NW China. Earth and Planetary Science Letters 254, 239-255.

Cowgill, E., Gold, R. D., Xuanhua, C., Xiao-Feng, W., Arrowsmith, J. R., Southon, J., 2009. Low Quaternary slip rate reconciles geodetic and geologic rates along the Altyn Tagh fault, northwestern Tibet. Geology 37 (7), $647-650$.

Dolan, J., Bowman, D., Sammis, C., 2007. Long-range and long-term fault interactions in Southern California. Geology 35 (9), 855-858.

Duvall, A. R., Clark, M. K., 2010. Dissipation of fast strike-slip faulting within and beyond northeastern Tibet. Geology 38 (3), 223-226. 
England, P., Molnar, P., 2005. Late Quaternary to decadal velocity fields in Asia. Journal of Geophysical Research 110 (B12).

Fay, N. P., Humphreys, E. D., 2005. Fault slip rates, effects of elastic heterogeneity on geodetic data, and the strength of the lower crust in the Salton Trough region, southern California. Journal of Geophysical Research-Solid Earth 110 (B9).

Feldl, N., Bilham, R., 2006. Great Himalayan earthquakes and the Tibetan plateau. Nature 444, 165-170.

Feng, G., Hetland, E. A., Ding, X., Li, Z., Zhang, L., 2010. Coseismic fault slip of the $2008 \mathrm{mw} 7.9$ wenchuan earthquake estimated from insar and gps measurements. Geophysical Research Letters 37 (1).

Flesch, L. M., Haines, A. J., Holt, W. E., 2001. Dynamics of the India-Eurasia collision zone. Journal of Geophysical Research 106 (B8), 16435-16460.

Forsyth, D., Uyeda, S., 1975. On the relative importance of the driving forces of plate motion. Geophysical Journal of the Royal Astronomical Society 43 (1), 163-200.

Friedrich, A. M., Wernicke, B. P., Niemi, N. A., Bennett, R. A., Davis, J. L., 2003. Comparison of geodetic and geologic data from the Wasatch region, Utah, and implications for the spectral character of Earth deformation at periods of 10 to 10 million years. Journal of Geophysical Research 108 (B4).

Gan, W., Zhang, P., Shen, Z.-K., Niu, Z., Wang, M., Wan, Y., Zhou, D., Cheng, J., 2007. Present-day crustal motion within the Tibetan Plateau inferred from GPS measurements. Journal of Geophysical Research 112. 
Haibing, L., Van der Woerd, J., Tapponnier, P., Klinger, Y., Xuexiang, Q., Jingsui, Y., Yintang, Z., 2005. Slip rate on the Kunlun fault at Hongshui Gou, and recurrence time of great events comparable to the 14/11/2001, Mw 7.9 Kokoxili earthquake. Earth and Planetary Science Letters 237 (12), $285-299$.

Hilley, G. E., Burgmann, R., Zhang, P. Z., Molnar, P., 2005. Bayesian inference of plastosphere viscosities near the Kunlun Fault, northern Tibet. Geophysical Research Letters 32 (1).

Hilley, G. E., Johnson, K., Wang, M., Shen, Z.-K., Bürgmann, R., 2009. Earthquake-cycle deformation and fault slip rates in northern Tibet. Geology 37 (1), 31-34.

Holt, W. E., Li, M., Haines, A. J., 1995. Earthquake strain rates and instantaneous relative motions within central and eastern Asia. Geophysical Journal International 122 (2), 569-593.

Jackson, J., 2002. Strength of the continental lithosphere: Time to abandon the jelly sandwich? GSA Today 12 (9), 4-10.

Jade, S., Bhatt, B. C., Yang, Z., Bendick, R., Gaur, V. K., Molnar, P., Anand, M. B., Kumar, D., 2004. GPS measurements from the Ladakh Himalaya, India: Preliminary tests of plate-like or continuous deformation in Tibet. Geological Society of America Bulletin 116 (11-12), 1385-1391.

Kirby, E., Harkins, N., Wang, E., Shi, X., Fan, C., Burbank, D., 2007. Slip rate gradients along the eastern Kunlun fault. Tectonics 26 . 
Kostrov, B. V., Das, S., 1988. Principles of earthquake source mechanics. Cambridge University Press, Cambridge.

Lamb, S. H., 1994. Behavior of the brittle crust in wide plate boundary zones. Journal of Geophysical Research 99 (B3), 4457-4483.

Langin, W. R., Brown, L. D., Sandvol, E. A., 2003. Seismicity of central Tibet from Project INDEPTH III seismic recordings. Bulletin of the Seismological Society of America 93 (5), 2146-2159.

Lasserre, C., Peltzer, G., CrampÈ, F., Klinger, Y., Van der Woerd, J., Tapponnier, P., 2005. Coseismic deformation of the $2001 M_{w}=7.8$ Kokoxili earthquake in Tibet, measured by synthetic aperture radar interferometry. Journal of Geophysical Research 110 (B12).

Lavé, J., Avouac, J. P., 2000. Active folding of fluvial terraces across the Siwaliks Hills, Himalayas of central Nepal. Journal of Geophysical Research 105 (B3), 5735-5770.

Lebedev, S., Nolet, G., 01 2003. Upper mantle beneath Southeast Asia from S velocity tomography. Journal of Geophysical Research 108 (B1).

Li, C., van der Hilst, R. D., Meltzer, A. S., Engdahl, E. R., 2008. Subduction of the Indian lithosphere beneath the Tibetan Plateau and Burma. Earth and Planetary Science Letters 274, 157-168.

Li, C., Zhang, P., Yin, J., Min, W., 2009. Late Quaternary left-lateral slip rate of the Haiyuan fault, northeastern margin of the Tibetan Plateau. Tectonics 28. 
Lohman, R. B., Simons, M., 2005. Locations of selected small earthquakes in the Zagros mountains. Geochemistry, Geophysics, Geosystems 6 (1).

Matsu'ura, M., Jackson, D. D., Cheng, A., 1986. Dislocation model for aseismic crustal deformation at Hollister, California. Journal of Geophysical Research 91 (B12), 2661-2674.

McCaffrey, R., 2002. Crustal block rotations and plate coupling. In: Stein, S., Freymueller, J. T. (Eds.), Plate Boundary Zones. Vol. 30 of Geodynamics Series. American Geophysical Union, pp. 101-122.

McCaffrey, R., 2005. Block kinematics of the Pacific-North America plate boundary in the southwestern United States from inversion of GPS, seismological, and geologic data. Journal of Geophysical Research 110 (B7).

Meade, B. J., 2007. Present-day kinematics at the India-Asia collision zone. Geology 35 (1), 81-84.

Meade, B. J., Hager, B. H., 2005. Block models of crustal motion in southern California constrained by GPS measurements. Journal of Geophysical Research 110.

Meade, B. J., Loveless, J. P., 2009. Block modeling with connected fault network geometries and a linear elastic coupling estimator in spherical coordinates. Bulletin of the Seismological Society of America 99 (6), 31243139.

Molnar, P., 1988. Continental tectonics in the aftermath of plate tectonics. Nature 335 (6186), 131-137. 
Murray, M. H., Segall, P., 2001. Modeling broadscale deformation in northern California and Nevada from plate motions and elastic strain accumulation. Geophysical Research Letters 28 (22), 4315-4318.

Okada, Y., 1985. Surface deformation due to shear and tensile faults in a half-space. Bulletin of the Seismological Society of America 75 (4), 11351154 .

Prawirodirdjo, L., Bock, Y., 2004. Instantaneous global plate motion model from 12 years of continuous GPS observations. Journal of Geophysical Research 109.

Prawirodirdjo, L., Bock, Y., McCaffrey, R., Genrich, J., Calais, E., Stevens, C., Puntodewo, S. S. O., Subarya, C., Rais, J., Zwick, P., Fauzi, 1997. Geodetic observations of interseismic strain segmentation at the Sumatra subduction zone. Geophysical Research Letters 24, 2601-2604.

Pritchard, M. E., Ji, C., Simons, M., 2006. Distribution of slip from 11 $M_{w}>6$ earthquakes in the northern Chile subduction zone. Journal of Geophysical Research 111.

Qinghai Bureau of Geology and Mineral Resources of Qinghai Province, 1991. Regional geology of Qinghai Province. Geological Publishing House, in Chinese with English abstract.

Raterman, N., Cowgill, E., Lin, D., 2007. Variable structural style along the Karakoram fault explained using triple-junction analysis of intersecting faults. Geosphere 3 (2), 71-85. 
Royden, L. H., Burchfiel, B. C., King, R. W., Wang, E., Chen, Z. L., Shen, F., Liu, Y. P., 1997. Surface deformation and lower crustal flow in eastern Tibet. Science 276 (5313), 788-790.

Savage, J. C., Burford, R. O., 1973. Geodetic determination of relative plate motion in central California. Journal of Geophysical Research 78 (5), 832845.

Savage, J. C., Gan, W. J., Svarc, J. L., 2001. Strain accumulation and rotation in the Eastern California Shear Zone. Journal of Geophysical Research 106 (B10), 21995-22007.

Sella, G. F., Dixon, T. H., Mao, A. L., 2002. REVEL: A model for Recent plate velocities from space geodesy. Journal of Geophysical Research 107 (B4).

Shen, J., Wang, Y., Song, F., 2003. Characteristics of the active Xiaojiang fault zone in Yunnan, China: a slip boundary for the southeastward escaping Sichuan-Yunnan Block of the Tibetan Plateau. Journal of Asian Earth Sciences 21, 1085-1096.

Shen, Z. K., Lu, J. N., Wang, M., Bürgmann, R., 2005. Contemporary crustal deformation around the southeast borderland of the Tibetan Plateau. Journal of Geophysical Research 110 (B11).

Solomon, S. C., Sleep, N. H., 1974. Some simple physical models for absolute plate motions. Journal of Geophysical Research 79, 2131-2153.

Souter, B. J., 1998. Comparisons of geologic models to GPS observations in 
southern California. PhD. thesis, Massachusetts Institute of Technology, Cambridge, MA.

Suppe, J., 2007. Absolute fault and crustal strength from wedge tapers. Geology 35 (12), 1127-1130.

Taylor, M., Peltzer, G., 2006. Current slip rates on conjugate strike-slip faults in central Tibet using synthetic aperture radar interferometry. Journal of Geophysical Research 111.

Taylor, M., Yin, A., 2009. Active structures of the Himalayan-Tibetan orogen and their relationships to earthquake distribution, contemporary strain field, and Cenozoic volcanism. Geosphere 5 (3), 199-214.

Thatcher, W., 2007. Microplate model for the present-day deformation of Tibet. Journal of Geophysical Research 112.

Thatcher, W., 2009. How the Continents Deform: The Evidence From Tectonic Geodesy. Annual Review of Earth and Planetary Sciences 37, 14.114.26 .

Thatcher, W. R., 2003. GPS constraints on the kinematics of continental deformation. International Geology Review 45 (3), 191-212.

Van der Woerd, J., Tapponnier, P., Ryerson, F., Meriaux, A., Meyer, B., Gaudemer, Y., Finkel, R., Caffee, M., Guoguang, Z., Zhiqin, X., 2002. Uniform postglacial slip-rate along the central $600 \mathrm{~km}$ of the Kunlun Fault (Tibet), from ${ }^{26} \mathrm{Al},{ }^{10} \mathrm{Be}$, and ${ }^{14} \mathrm{C}$ dating of riser offsets, and climatic origin of the regional morphology. Geophysical Journal International 148 (3), 356-388. 
Vigny, C., Socquet, A., Rangin, C., Chamot-Rooke, N., Pubellier, M., Bouin, M. N., Bertrand, G., Becker, M., 2003. Present-day crustal deformation around Sagaing fault, Myanmar. Journal of Geophysical Research 108 (B11).

Wang, Q., Zhang, P. Z., Freymueller, J. T., Bilham, R., Larson, K. M., Lai, X., You, X. Z., Niu, Z. J., Wu, J. C., Li, Y. X., Liu, J. N., Yang, Z. Q., Chen, Q. Z., 2001. Present-day crustal deformation in China constrained by global positioning system measurements. Science 294 (5542), 574-577.

Wang, S., Wang, E., Fang, X., Fu, B., 2008. Late Cenozoic systematic leftlateral stream deflections along the Ganzi-Yushu Fault, Xianshuihe Fault System, eastern Tibet. International Geology Review 50, 624-635.

Wen, X., Xu, X., Zheng, R., Xie, Y., Wan, C., 2003. Average slip-rate and recent large earthquake ruptures along the Garzê-Yushu fault. Science in China Series D-Earth Sciences 46, 276-288.

Xu, X., Wen, X., Yu, G., Chen, G., Klinger, Y., Hubbard, J., Shaw, J., 2009. Coseismic reverse- and oblique-slip surface faulting generated by the 2008 Mw 7.9 Wenchuan earthquake, China. Geology 37 (6), 515-518.

Zhang, P. Z., Shen, Z., Wang, M., Gan, W. J., Burgmann, R., Molnar, P., 2004. Continuous deformation of the Tibetan Plateau from global positioning system data. Geology 32 (9), 809-812. 


\begin{tabular}{|c|c|c|c|c|c|c|c|c|}
\hline \multirow[b]{2}{*}{ Block $^{a}$} & \multirow[b]{2}{*}{ Name } & \multicolumn{3}{|c|}{ Joint inversion $^{b}$} & \multicolumn{2}{|c|}{ Geodetic-only $^{c}$} & \multicolumn{2}{|c|}{ Est. strain rate ${ }^{d}$} \\
\hline & & $\phi$ & IDL & $\phi_{\mathrm{ID}}{ }^{e}$ & $\phi$ & IDL & $\phi$ & IDL \\
\hline $\mathrm{A}$ & Himalayan Range & 28.1 & 99.1 & 10.1 & 29.0 & 98.2 & 2.2 & 0 \\
\hline B & Karakorum & 61.4 & 5.0 & 0 & 63.3 & 3.2 & 53.4 & 0.1 \\
\hline $\mathrm{C}$ & Jiali & 66.2 & 49.0 & 0 & 66.6 & 47.0 & 64.2 & 15.9 \\
\hline $\mathrm{D}$ & West-central Plateau & 86.0 & 98.3 & 73.0 & 85.7 & 98.4 & 51.1 & 0 \\
\hline $\mathrm{E}$ & East-central Plateau & 63.1 & 6.7 & 0 & 63.9 & 6.4 & 33.9 & 0 \\
\hline $\mathrm{F}$ & Qaidam Basin & 54.2 & 2.0 & 0 & 56.9 & 2.3 & 30.1 & 0 \\
\hline G & Qilian Shan & 62.2 & 15.4 & 0 & 65.8 & 15.9 & 15.9 & 0 \\
\hline $\mathrm{H}$ & Elashan & 68.6 & 0.4 & 0 & 74.0 & 0.3 & 40.5 & 0 \\
\hline $\mathrm{I}$ & Gonghe Nan Shan & 66.6 & 38.8 & 0 & 72.4 & 29.7 & 38.2 & 0.4 \\
\hline $\mathrm{J}$ & West Qinling & 46.3 & 10.8 & 0 & 55.7 & 4.1 & 20.1 & 0 \\
\hline $\mathrm{K}$ & Haiyuan & 62.1 & 0 & 0 & 62.1 & 0 & 15.3 & 0 \\
\hline $\mathrm{L}$ & Ordos Plateau & 72.8 & 0 & 0 & 73.4 & 0 & 26.8 & 0 \\
\hline M & Lanzhou & 68.7 & 0 & 0 & 71.3 & 0 & 29.4 & 0 \\
\hline $\mathrm{N}$ & Ganzi-Xianshuihe & 71.3 & 95.4 & 53.2 & 61.5 & 88.7 & 43.0 & 8.6 \\
\hline $\mathrm{O}$ & Lugu Lake & 64.8 & 0.1 & 0 & 67.6 & 0.1 & 10.8 & 0 \\
\hline $\mathrm{P}$ & Eastern Kunlun & 56.7 & 2.5 & 0 & 48.8 & 2.3 & 45.5 & 0.2 \\
\hline $\mathrm{Q}$ & Longmenshan & 59.4 & 33.4 & 0 & 62.5 & 32.3 & 31.0 & 0 \\
\hline $\mathrm{R}$ & Anninghe-Daliangshan & 47.5 & 11.6 & 0 & 50.0 & 13.2 & 15.7 & 0.1 \\
\hline $\mathrm{S}$ & South China & 24.8 & 0 & 0 & 24.9 & 0 & 10.8 & 0 \\
\hline $\mathrm{T}$ & Yunnan & 56.7 & 0.7 & 0 & 56.6 & 0.7 & 53.9 & 0 \\
\hline $\mathrm{U}$ & Burma & 73.4 & 54.5 & 5.9 & 73.5 & 54.7 & 64.7 & 0 \\
\hline $\mathrm{V}$ & Laos & 64.2 & 9.9 & 0 & 64.4 & 10.0 & 69.2 & 2.5 \\
\hline $\mathrm{W}$ & Aksai Chin & 90.3 & 67.9 & 64.4 & 91.4 & 65.4 & 89.1 & 61.5 \\
\hline $\mathrm{X}$ & Tarim Basin & 56.2 & 2.5 & 0 & 58.4 & 2.2 & 11.6 & 0 \\
\hline
\end{tabular}

Table 1: Summary of potency rate partitioning parameters, expressed here as percentages. Superscripts refer to information contained in corresponding figures: ${ }^{a}$ Figure $1 ;{ }^{b}$ Figure 7 ;

${ }^{c}$ Figure S1; ${ }^{d}$ Figure S2; ${ }^{e}$ Figure $7 \mathrm{c}$. 


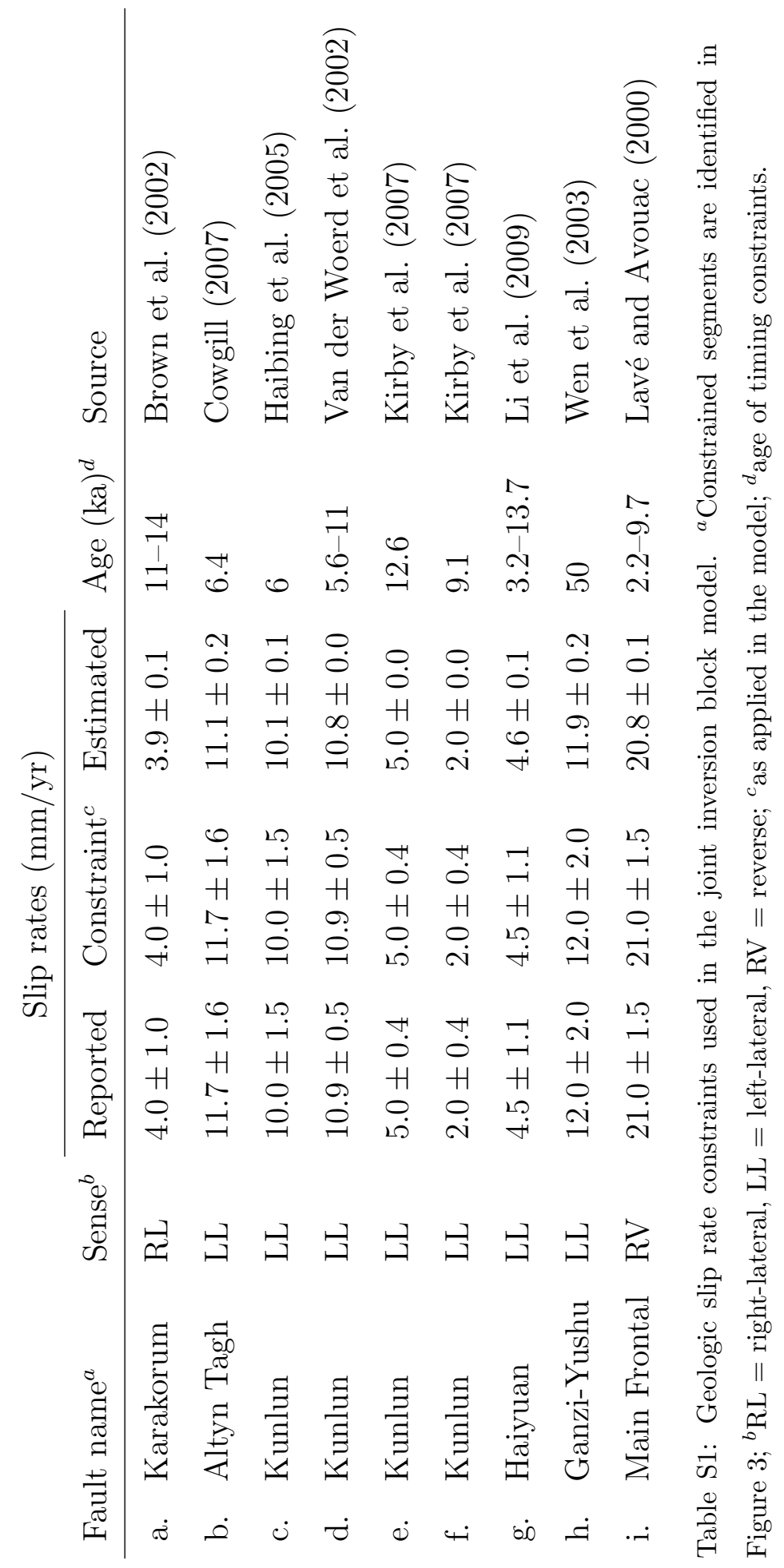




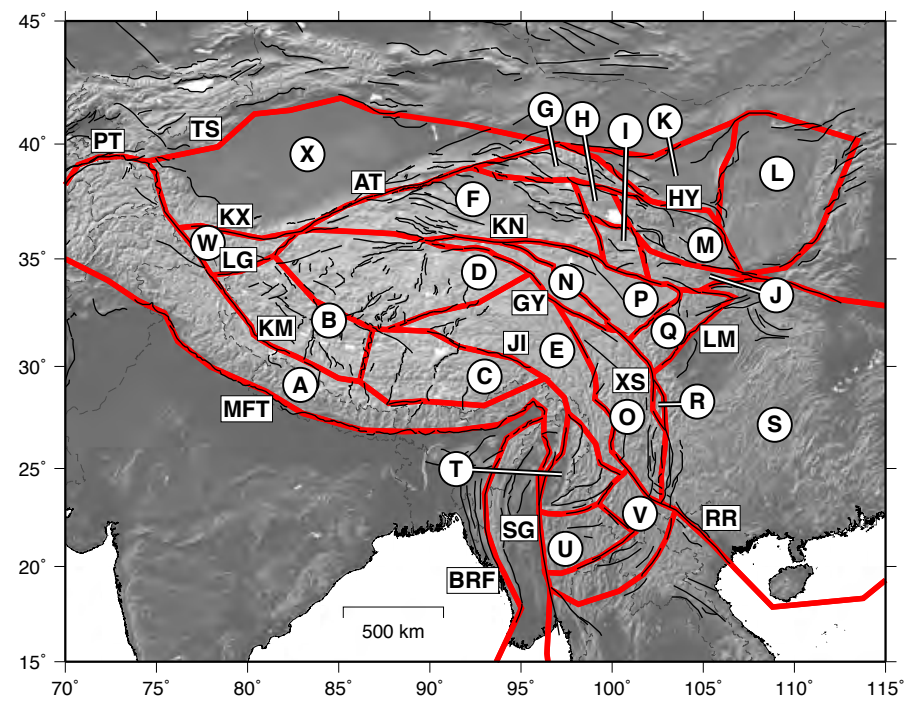

Figure 1: Active faults (black lines; Taylor and Yin, 2009) and reference model block geometry (red lines, with blocks identified by circled letters). Major faults labeled are the Main Frontal Thrust (MFT), Karakorum (KM), Longmu-Gozha (LG), Karakax (KX), Pamir Thrust (PT), Tien Shan range front (TS), Altyn Tagh (AT), Jiali (JI), GanziYushu (GY), Burman Range Front (BRF), Sagaing (SG), Red River (RR), Xianshuihe (XS), Longmenshan range front (LM), Kunlun (KN), and Haiyuan (HY). The blocks are labeled as: Himalayan Range (A), Karakorum (B), Jiali (C), west-central plateau (D), eastcentral plateau (E), Qaidam Basin (F), Qilian Shan (G), Elashan (H), Gonghe Nan Shan (I), West Qinling (J), Haiyuan (K), Ordos Plateau (L), Lanzhou (M), Ganzi-Xianshuihe sliver (N), Lugu Lake (O), eastern Kunlun (P), Longmenshan (Q), Anninghe-Daliangshan sliver (R), south China (S), Yunnan (T), Burma (U), Laos (V), Aksai Chin (W), and Tarim Basin $(\mathrm{X})$. 


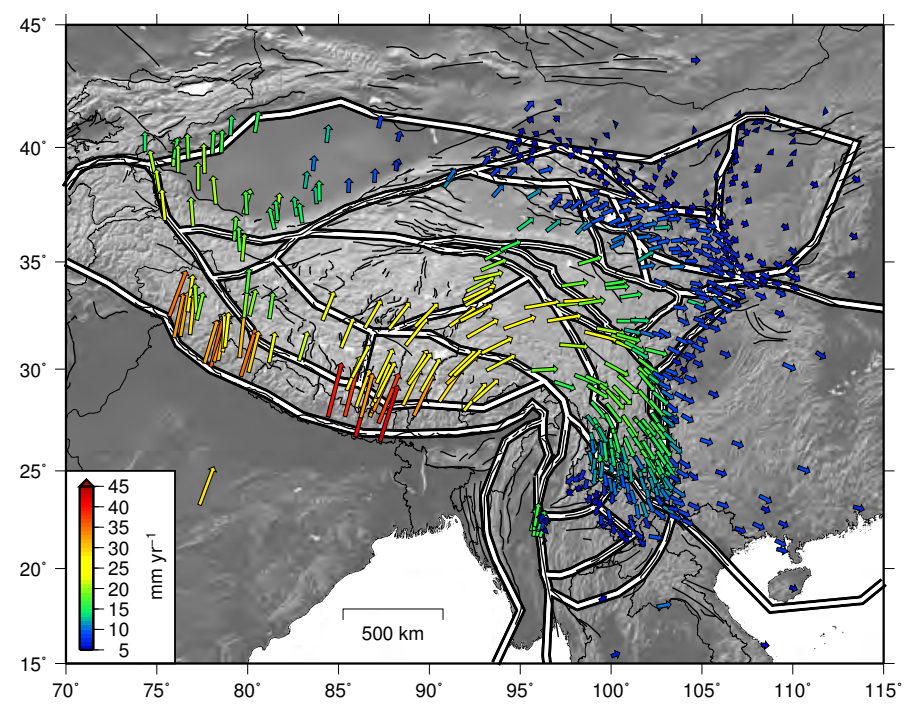

Figure 2: Nominally interseismic GPS velocities. We combined the velocity fields of Vigny et al. (2003), Calais et al. (2006), and Gan et al. (2007) into a common reference frame by finding rotation and translation parameters that minimize the difference between velocities at collocated stations. Velocities are listed in Table S2. 

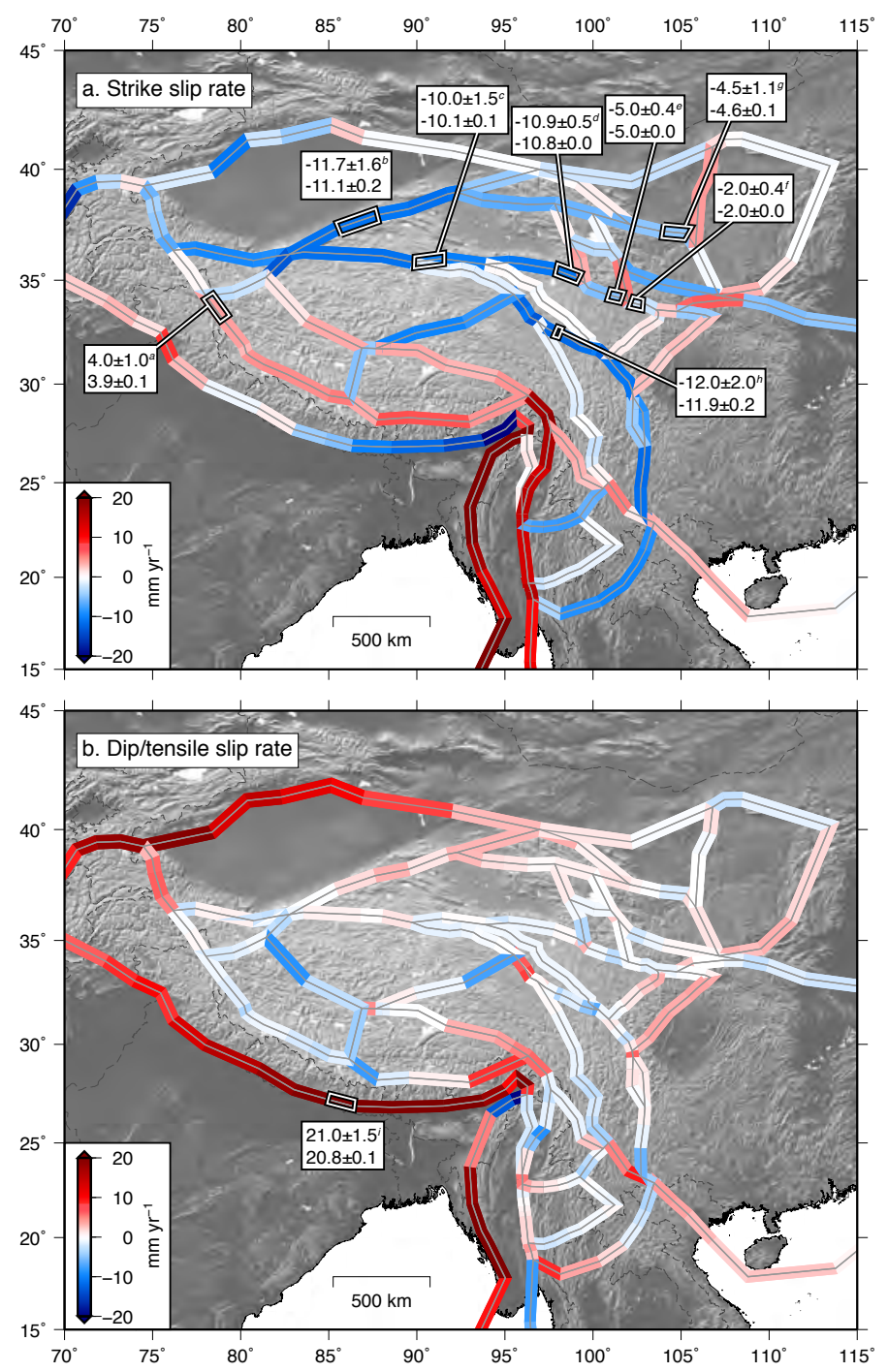

Figure 3: Estimated a) strike and b) dip/tensile fault slip rates from the combined geodeticgeologic block model inversion. Right-lateral and reverse/closing sense slip are given as positive. Outlined fault segments indicate locations of geologic slip rate constraints, with the label giving the input (top) and estimated (bottom) rates and uncertainties. Superscripts give source of slip rate constraint: ${ }^{a}$ Brown et al. (2002); ${ }^{b}$ Cowgill (2007); ${ }^{c}$ Haibing et al. (2005); ${ }^{d}$ Van der Woerd et al. (2002); ${ }^{e, f}$ Kirby et al. (2007); ${ }^{g}$ Li et al. (2009); ${ }^{h}$ Wen et al. (2003); ${ }^{i}$ Lavé and Avouac (2000). 

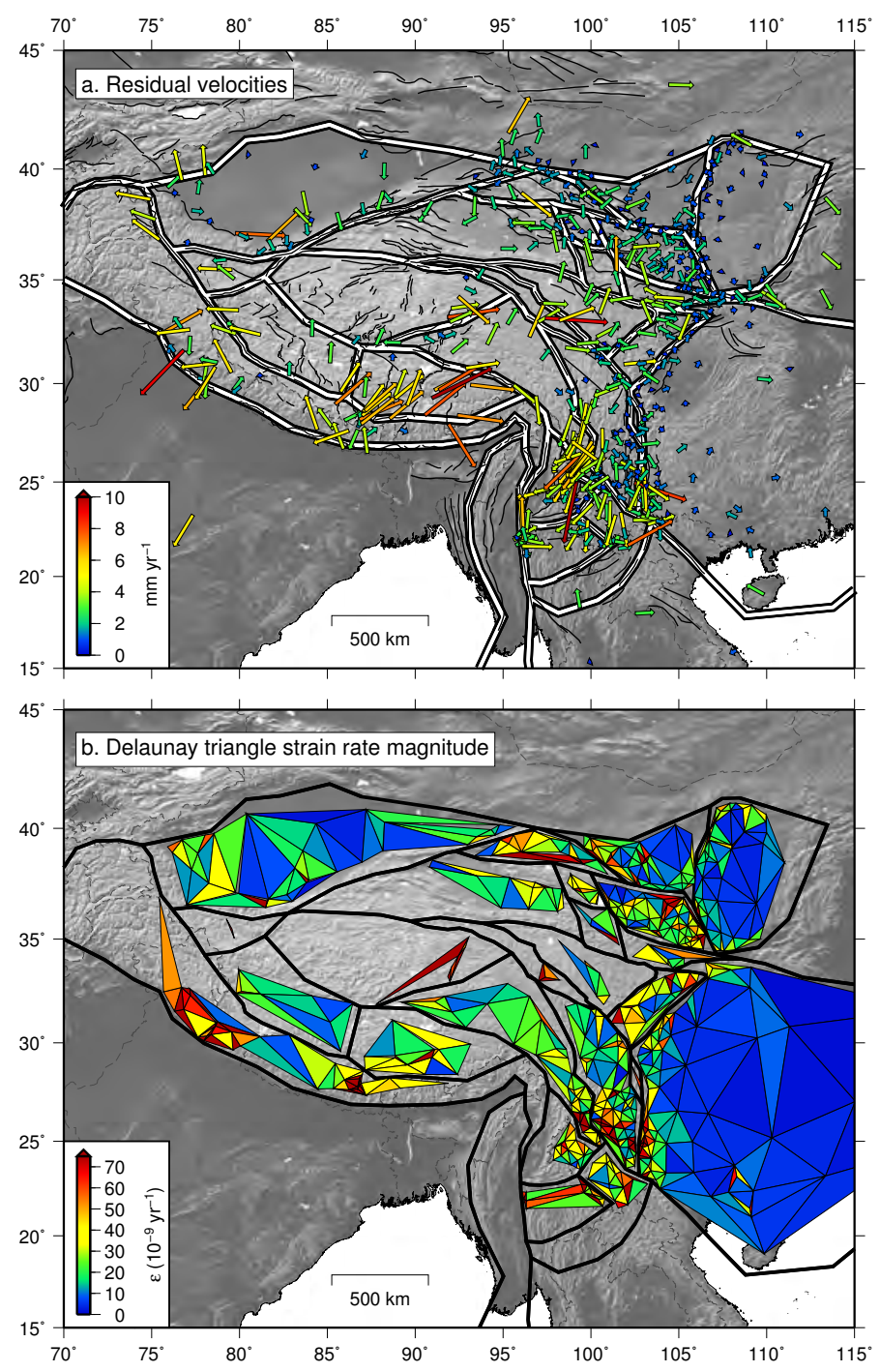

Figure 4: a) Residual velocities from the joint geodetic-geologic inversion. Velocities are listed in Table S2. b) Delaunay triangulation of residual velocity field. Colors give the magnitude of the strain rate tensor within each triangle; we assume that strain is homogeneous within each element. Triangles whose sides cross block boundaries are discarded. 


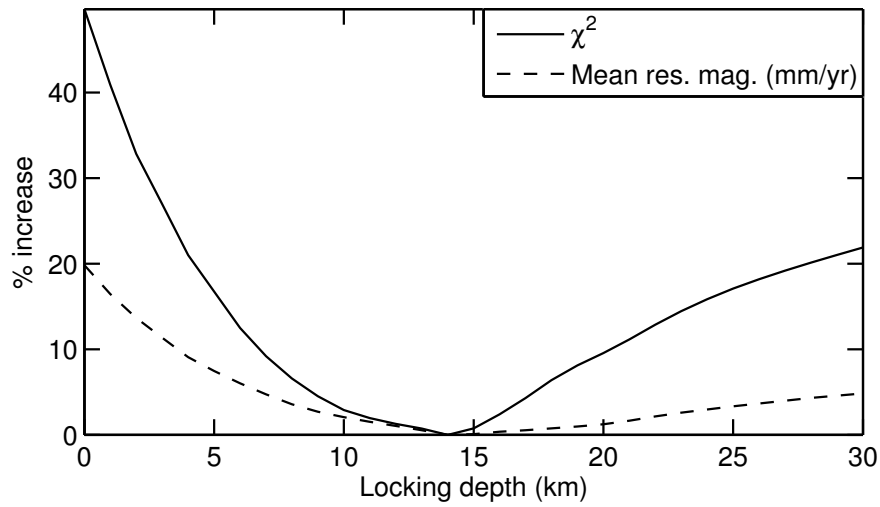

Figure 5: Residual velocity statistics as a function of fault locking depth. We vary the locking depth of all fault segments between 0 and $30 \mathrm{~km}$ and find that which minimizes the residual velocity field $(14 \mathrm{~km})$, here expressed as the percent increase above the minimum $\chi^{2}$ value (solid) and mean residual velocity magnitude (dashed). 

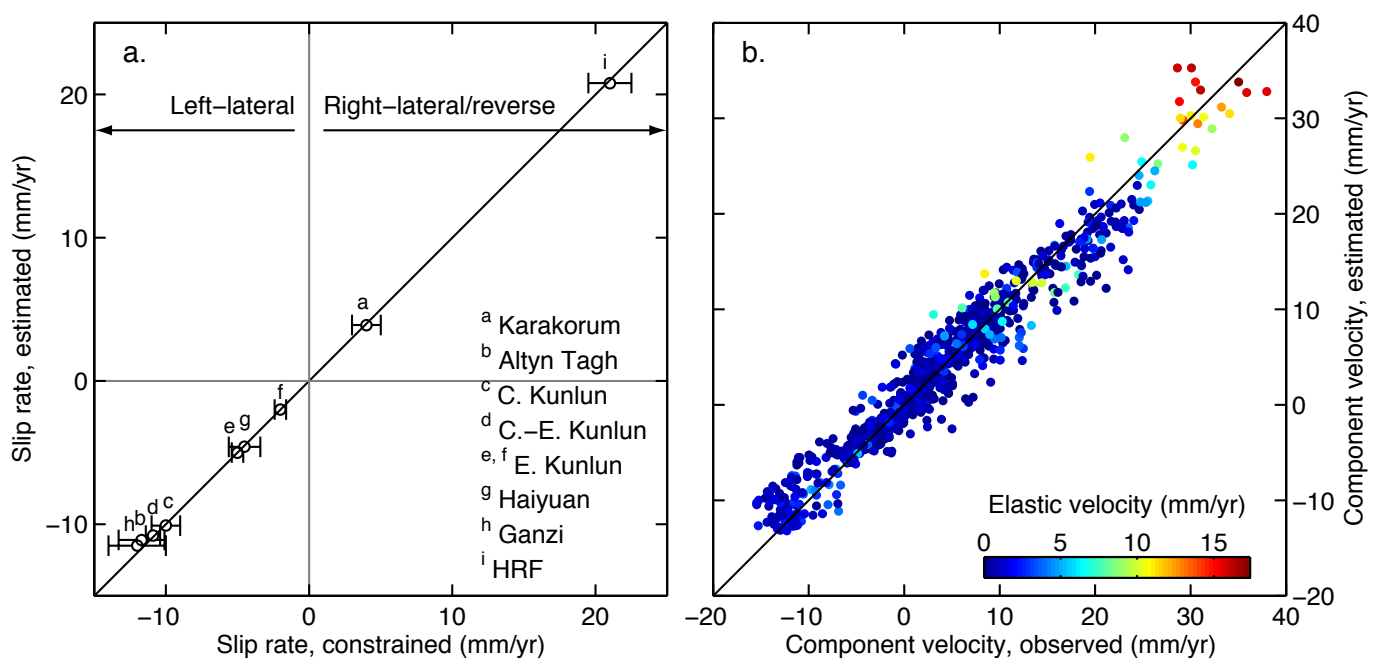

Figure 6: Constraining and estimated geologic and geodetic data. a) Geologic fault slip rates used as constraints versus estimated rates. Reported uncertainties are shown; estimated uncertainties are not. Segments are labeled in Figure 3. b) Observed versus estimated GPS component velocities within the plateau micro-plates. Color denotes magnitude of velocity contribution from elastic earthquake cycle processes. In both panels, a 1:1 relationship is given by the black line. 

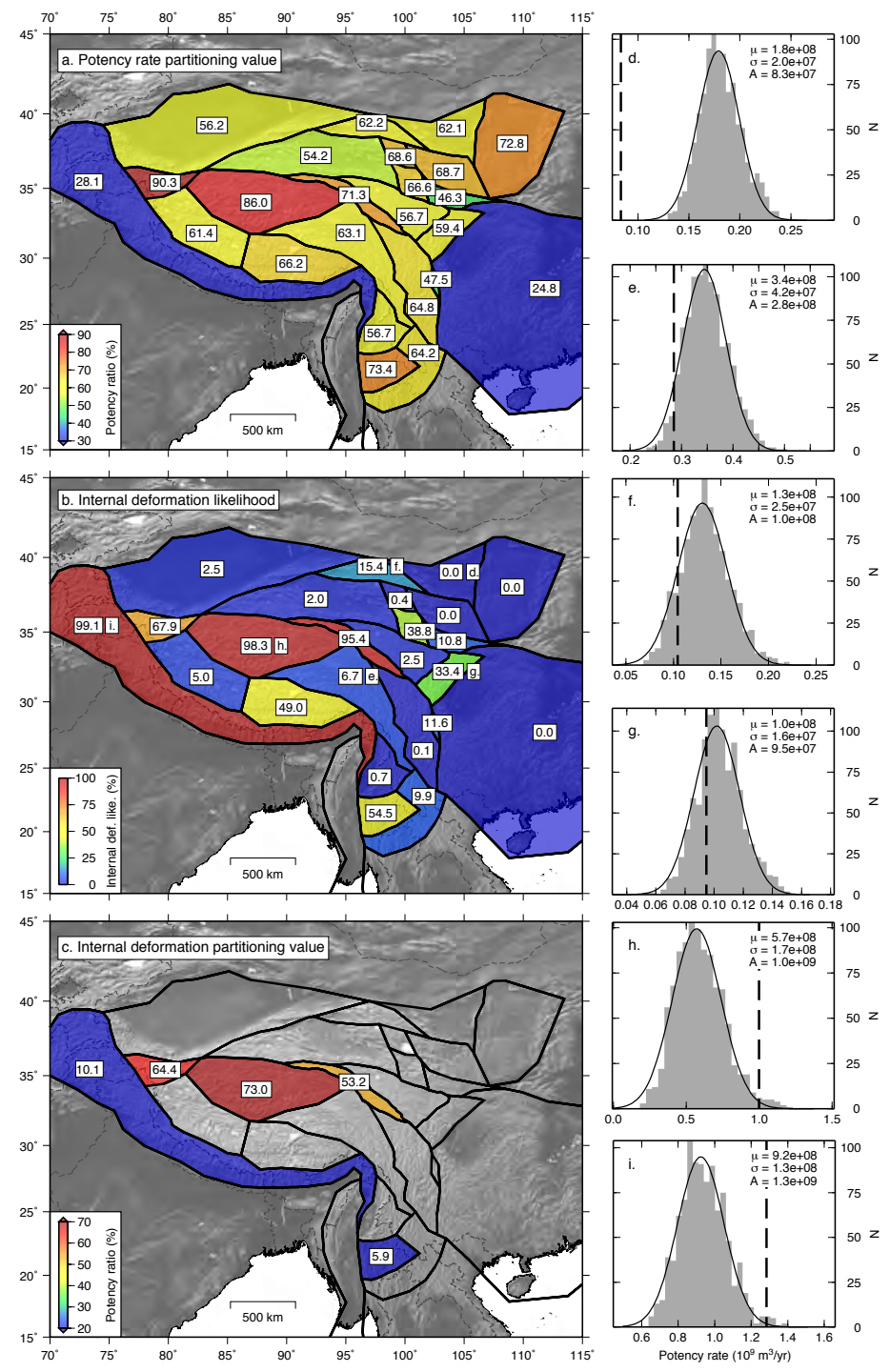

Figure 7: a) Potency rate partitioning values, $\phi$, given as the intrablock percentage of the total potency rate, based on the gradient of the residual velocity field from the joint geodetic-geologic inversion. b) Internal deformation likelihood (IDL), given as the percent of Monte Carlo simulation trials whose intrablock potency rate magnitude is less than the rate from the reference model residual velocity gradient. c) Percentage of total potency rate accommodated by internal deformation that is statistically distinct from observational noise, $\left.\phi_{\mathrm{ID}} \cdot \mathrm{d}-\mathrm{i}\right)$. Example histograms showing the frequency distribution of intrablock potency rates from the 1000 Monte Carlo trials. The corresponding blocks are labeled in panel b. In each of the histogram panels, the black solid curve shows the best-fitting Gaussian distribution of the histogram and the black dashed line shows the actual potency rate from the joint inversion. The mean and standard deviation of the distribution, and the actual potency rate, are given as $\mu, \sigma$, and $\mathrm{A}$, respectively. 


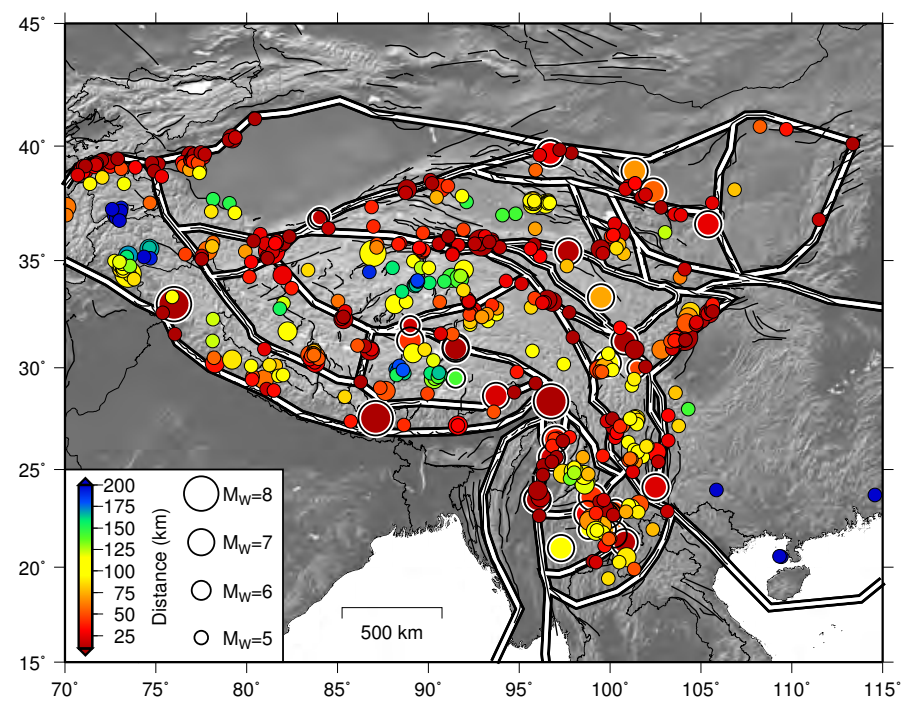

Figure 8: Distance between modern (Global CMT catalog earthquakes with depth $\leq 33 \mathrm{~km}$ and $\mathrm{M}_{\mathrm{W}} \geq 5.0$ ) and historical (white outlined circles, $\mathrm{M}_{\mathrm{W}} \geq 6.4$ from Holt et al. (1995)) earthquakes and the surface trace of the nearest block geometry fault segment, scaled by magnitude. Only earthquakes within the greater plateau region are plotted. 

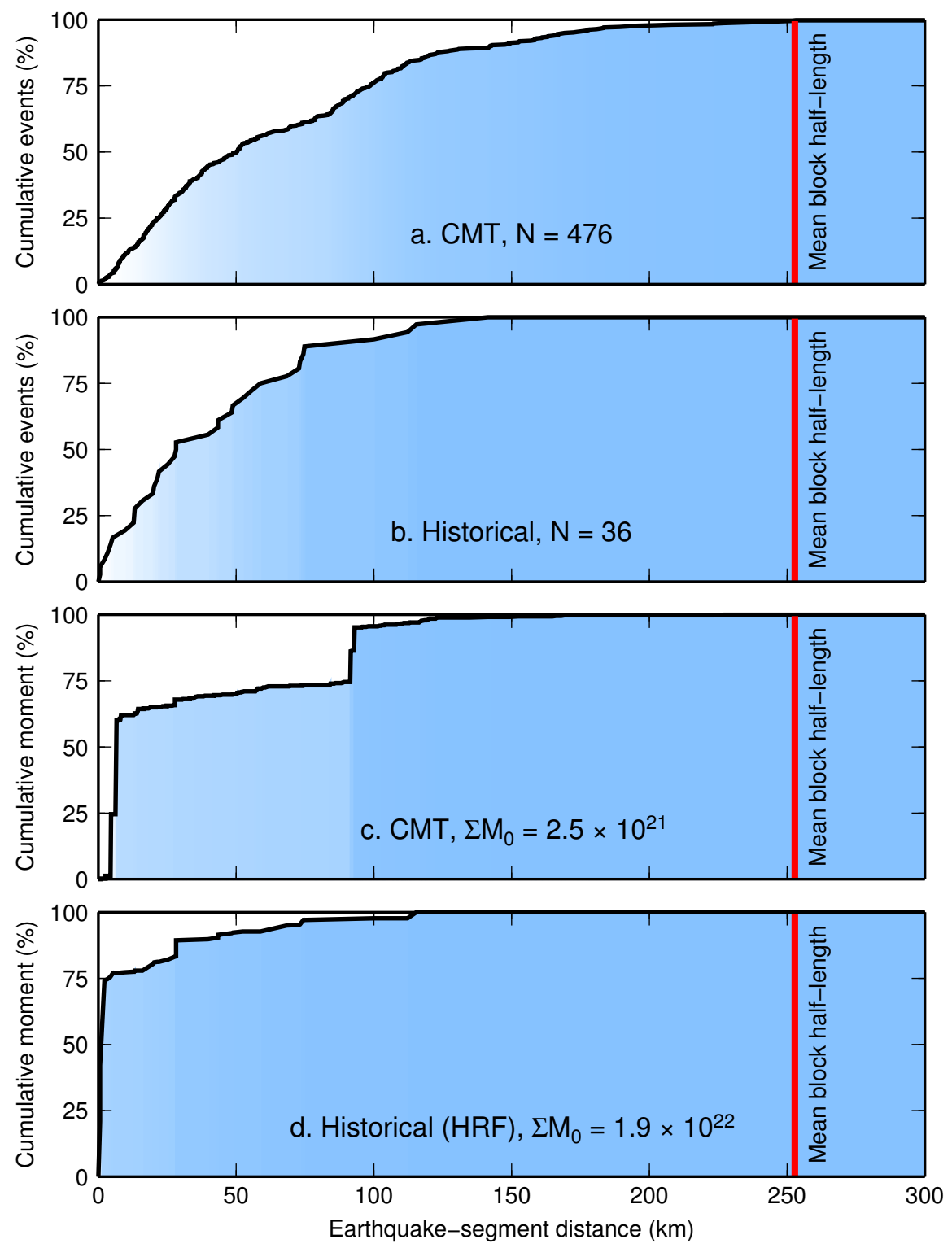

Figure 9: Spatial distribution statistics of crustal earthquakes shown in Figure 8. a, b) Cumulative number of events within a given distance range of the nearest block geometry fault segment for modern (a) and historical (b) earthquakes. Half of modern and $2 / 3$ of the historical events occur within $50 \mathrm{~km}$ of a block boundary. c, d, e) Percent of cumulative moment released vs. distance for modern (b) and historical (d, e) earthquakes. Sixty-six percent of the total modern moment is released within $25 \mathrm{~km}$ of a fault segment, and $96 \%$ is released within $100 \mathrm{~km}$ of a fault segment. Assuming that the three largest historical earthquakes occurred on the dipping Himalayan Range Front (HRF) thrust, $89 \%$ of the historical moment has been released within $25 \mathrm{~km}$ of block boundaries (d). The red vertical line represents a mean linear block dimension, given as half the mean of the square roots of the plateau blocks' areas $(253 \mathrm{~km})$, and represents an average distance between a block interior and its boundaries. 

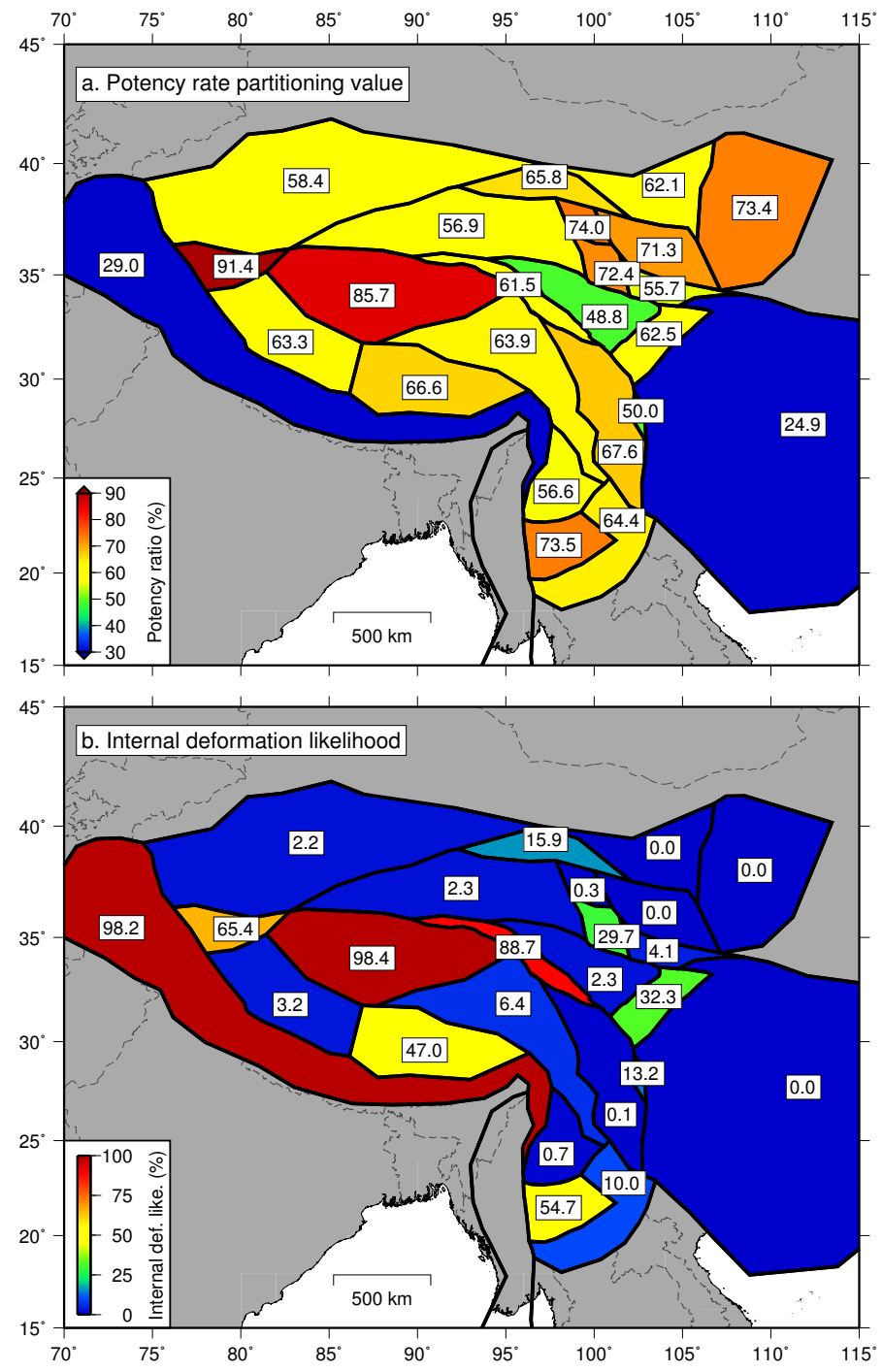

Figure S1: Potency rate partitioning ratio, $\phi$ (a), and IDL (b) values based on the residual velocity gradient from the geodetic-only inversion, expressed as percentages. 

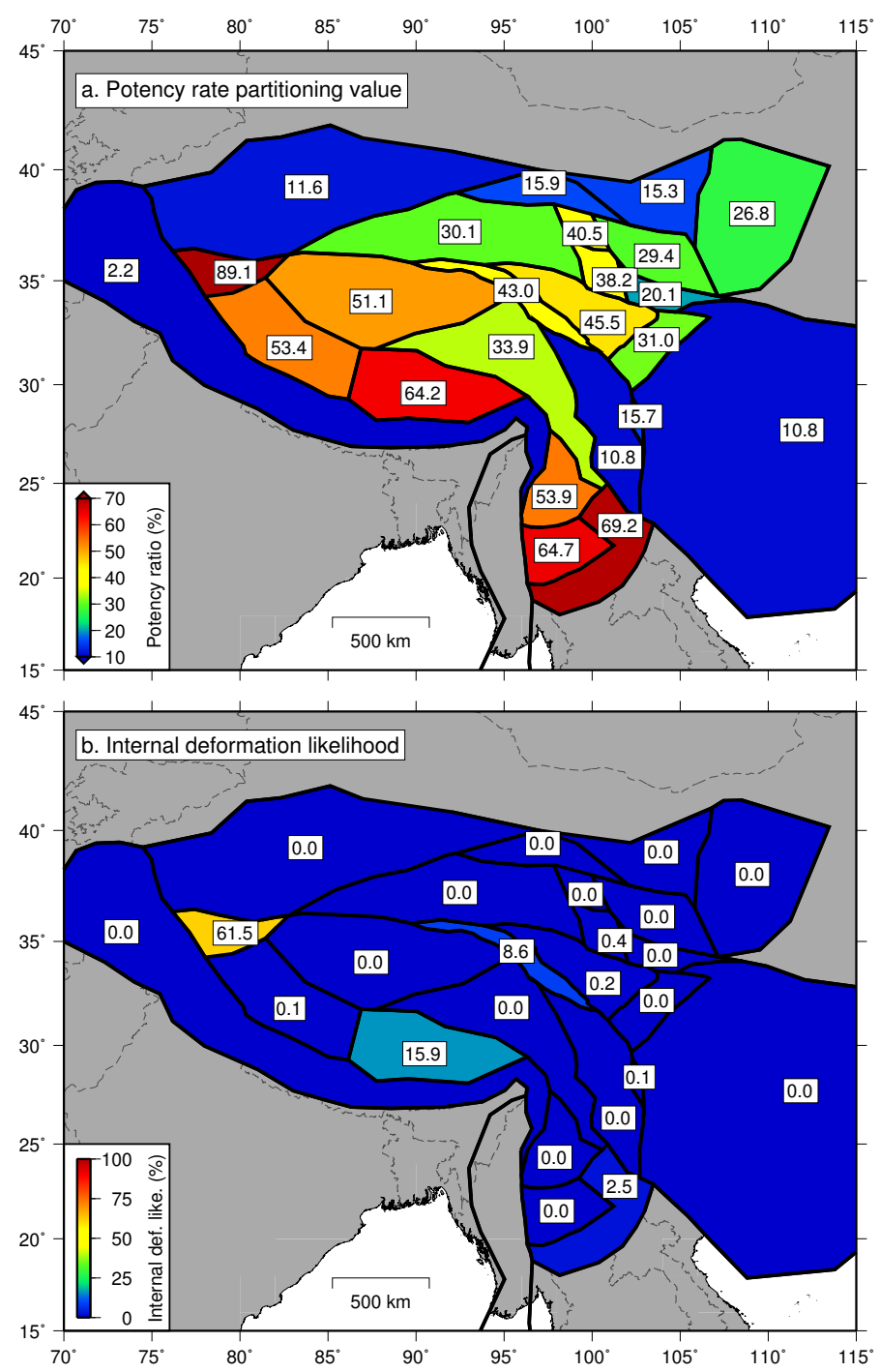

Figure S2: Potency rate partitioning ratio, $\phi(a)$, and IDL (b) values based on the bestfitting strain rate tensor estimated within each block based on a joint geodetic-geologic inversion, expressed as percentages. 

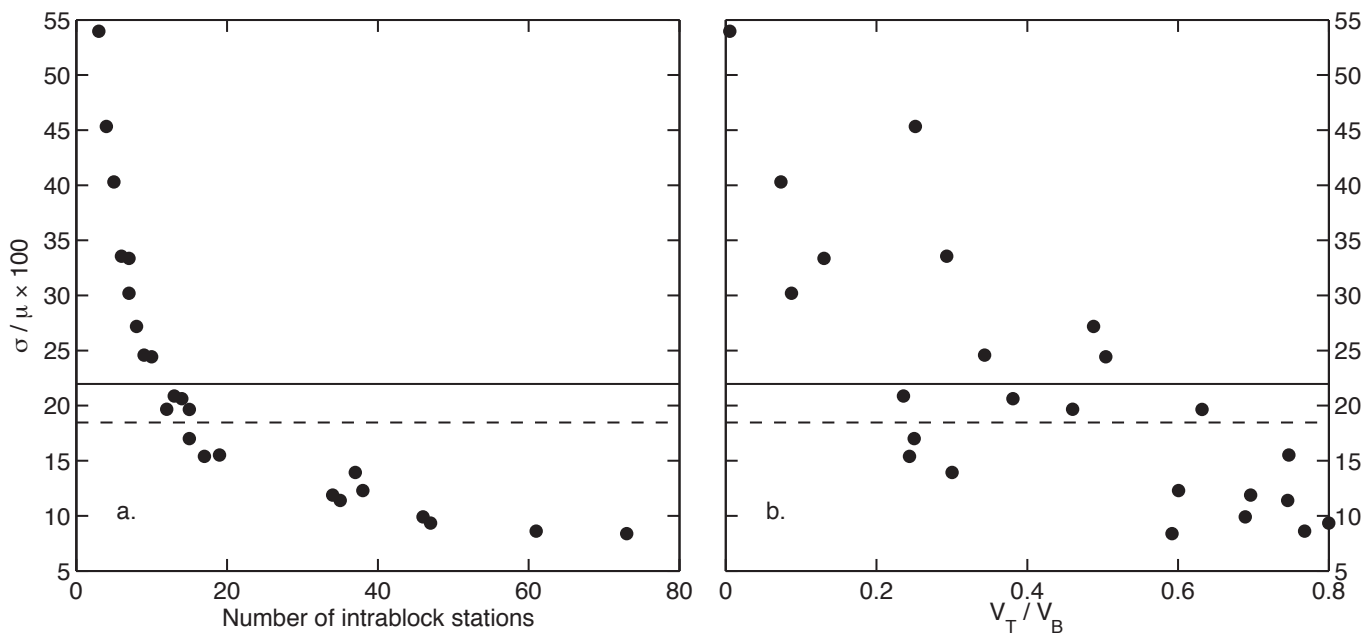

Figure S3: Variation in internal potency rates from Monte Carlo simulations. For each block, the standard deviation, $\sigma$, of all trial potency rates, normalized by the mean, $\mu$, is plotted versus the a) number of stations within the block and b) percent of the block's volume, $V_{\mathrm{B}}$, occupied by the volume of all Delaunay triangle prisms, $V_{\mathrm{T}}$. The Aksai Chin, Anninghe-Daliangshan, and Ganzi-Xianshuihe blocks contain only 3, 4, and 5 stations, respectively, and they show substantially higher normalized standard deviation in the simulated potency rate ( $>40 \%$ of the mean) than do other blocks. Variation decreases with increasing number of stations (a) and in general decreases with increasing Delaunay fractional block volume (b). The average normalized standard deviation for all blocks is shown as the solid horizontal line (22.0\%); the dashed line gives the mean value (18.5\%) excluding the three blocks with normalized standard deviations $>40 \%$. 


\section{Appendix A. Reference model block geometry description}

The Himalayan Range block (block A on Figure 1) is bounded by the Main Frontal Thrust (MFT) and the Karakorum fault (KM); we model KM as extending east of $85^{\circ} \mathrm{E}$, roughly parallel to the MFT. Both faults bend around the eastern syntaxis at Namche Barwa, merging with the Sagaing fault (SG) and Burman Range Front (BRF) around $95^{\circ} \mathrm{E}$. Immediately north of the Himalayan Range block, we model the Karakorum (B) and Jiali (C) blocks, bounded to the south by KM and its eastern extension and to the north by the Jiali fault (JI) and its westward continuation beyond $85^{\circ} \mathrm{E}$, which follows a few short mapped fault segments. Separating the Karakorum and Jiali blocks at $85^{\circ} \mathrm{E}$ is a north-south striking structure mapped by Taylor and Yin (2009) as a series of normal faults. North of these blocks are the west-central plateau and east-central plateau blocks (D and E, respectively), bounded to the north by the western Kunlun fault (KN) and the Ganzi-Yushu fault (GY). Separating blocks the west- and east-central plateau blocks is a northeast striking structure connecting JI to GY, which follows a discontinuous trace on the active fault and modern seismicity maps (Taylor and Yin, 2009). North of the west-central plateau blocks, bounded by the Kunlun fault on the south, the Altyn Tagh fault (AT) on the west, and faults of the Qaidam thrust belt to the north, is the Qaidam Basin block (F). To its north is the Qilian Shan block (G), and to the east are the Elashan (H), Gonghe Nan Shan (I), West Qinling (J), Haiyuan (K), Ordos Plateau (L), and Lanzhou (M) blocks, whose boundaries are defined by reasonably contiguous fault networks, including the Haiyuan fault (HY). To the north and east of the east-central plateau block are the Ganzi-Xianshuihe sliver (block N) and 
Lugu Lake block (O), whose boundaries are KN, GY and a south-southeast striking branch leading to the Red River fault (RR), and the Xianshuihe fault (XS). The Eastern Kunlun block (P) is triangular in shape and lies between the eastern KN, northern XS, and the fault west of the Longmenshan foldand-thrust belt (LM); east of the Eastern Kunlun block is the Longmenshan proper (block Q). The Anninghe-Daliangshan block (R) lies between two segments of the XS, and the south China block (S) lies to its east. The Yunnan (T), Burma (U), and Laos (V) blocks are located in southeast Asia, where GPS data are sparse. The Aksai Chin block (W) is located about $80^{\circ} \mathrm{E}$, between the Longmu-Gozha fault (LG), the Karakax fault (KX), and the western KM. Finally, the Tarim Basin block (X) lies between KX, AT, and the southern edge of the Tien Shan (TS). 